\title{
A OCUPAÇÃo DA IDADE DO FERRO DE CACILHAS (Almada, Portugal)
}

\section{Cacilhas's Iron Age Occupation (Almada, Portugal)}

\author{
Ana Olaio \\ Divisão de Museus da Câmara Municipal de Almada.
}

Pedro Angeja

Arqueólogo.

Rui SOARES

FCT. UNIARQ - Centro de Arqueologia da Universidade de Lisboa.

PedRo VAlÉRIO

Centro de Ciências e Tecnologias Nucleares, Instituto Superior Técnico, Universidade de Lisboa.

Recibido: 11/06/2018

Revisado: 20/05/2019
Aceptado: 29/05/2019

Publicado: 05/07/2019

\section{RESUMO}

As diversas intervenções realizadas em Cacilhas entre os anos 80 e 90 do século XX revelaram uma longa diacronia de ocupação do espaço que recua, pelo menos, à Idade do Ferro. O espólio recolhido nas áreas intervencionadas é numeroso e constitui-se essencialmente por cerâmicas, tendo ainda sido identificado um cadinho e uma faca em ferro. $\mathrm{O}$ interesse destes vestígios é reforçado pela localização de Cacilhas numa área com potencialidades naturais de ancoragem e pela proximidade relativamente ao povoado da Quinta do Almaraz.

$\mathrm{O}$ presente trabalho pretende dar a conhecer o conjunto de materiais pré-romanos recolhidos em Cacilhas, integrando-o nas dinâmicas que ocorrem na primeira metade do $1^{0}$ milénio a.C. no Estuário do Tejo, bem como analisar as estruturas escavadas face à sua função e ligação ao povoado da Quinta do Almaraz.

\section{PALAVRAS-CHAVE}

Idade do Ferro; Estuário do Tejo; Produção local; Quinta do Almaraz; Cais.

\section{ABSTRACT}

The archaeological interventions carried out in Cacilhas during the 1980s and 1990s have unearthed a pattern of prolonged occupation dating back to the Iron Age. These excavations have yielded large quantities of pottery, the bulk of assemblage recovered, which also includes a crucible and an iron knife. These finds become increasingly relevant when Cacilhas' location in a natural docking area and its proximity to the Quinta do Almaraz settlement are taken into account.

This paper aims to evidence the pre-roman finds collected in Cacilhas, analyse the features encountered, in relation to their use and their connection to Almaraz, all the while integrating them in the backdrop of the first half of the 1st millennium $\mathrm{BCE}$ in the Tejo estuary.

\section{KEY WORDS}

Iron Age; Tagus estuary; Local production; Quinta do Almaraz; Pier. 


\section{NotA INTRODUTÓRIA}

As diversas intervenções arqueológicas realizadas entre 1981 e 1997 em Cacilhas (Almada, Portugal) revelaram uma longa diacronia de ocupação, que recua, pelo menos, ao $1^{0}$ milénio a.C.. As referências a este sítio centraram-se essencialmente na identificação de uma unidade de exploração de preparados piscícolas de época romana - a primeira identificada no Tejo -, ainda que desde as primeiras notícias se tenha reconhecido uma ocupação da Idade do Ferro (Barros e Amaro, 1985).

A proximidade relativamente ao povoado da Quinta do Almaraz, bem como a referência à identificação de um «cais pré-romano» no local (Barros e Henriques, 1998), revestem os contextos alusivos ao $1^{\circ}$ milénio a.C. de especial interesse. Esta é uma área bastante resguardada, com acesso privilegiado ao Estuário do rio Tejo e ao denominado "mar da palha" (figura 1), autêntico mar interior e fundeadouro natural de águas calmas, a partir do qual se desenvolvia uma rede de vias fluviais que facilitavam a comunicação com o Estuário do Sado. Estas condições tornam Cacilhas um local com potencialidades naturais de ancoragem, sendo ainda, na actualidade, um dos mais importantes pontos de ligação com Lisboa pelo rio.

$\mathrm{O}$ presente estudo incide assim sobre o conjunto de materiais da Idade do Ferro recolhido durante as referidas intervenções e depositado no Museu de Arqueologia e História Local da Câmara Municipal de Almada (adiante designada "CMA")1.

\section{RESUMO DOS TRABALHOS E ESTRUTURAS}

\section{IDENTIFICADAS}

Os primeiros vestígios de ocupação antiga de Cacilhas, relativos à fábrica romana de salga de peixe, foram identificados em 1981 por membros do Centro de Arqueologia de Almada (adiante designado "CAA") no âmbito do acompanhamento de obras de saneamento (Barros, 1982). A urgência dos trabalhos e o facto de, à época, o CAA estar dependente do trabalho voluntário dos seus associados, inviabilizou a possibilidade de escavação sistemática da área. Deste modo, procedeu-se apenas ao registo das estruturas e à recolha de algum espólio que pudesse caracterizar genericamente o sítio (Barros e Amaro, 1985).

1 Existe um pequeno conjunto de artefactos das intervenções de Cacilhas depositados no Centro de Arqueologia de Ảlmada. Porém, o Grupo Coordenador do CAA não autorizou o acesso por se encontrarem em estudo.

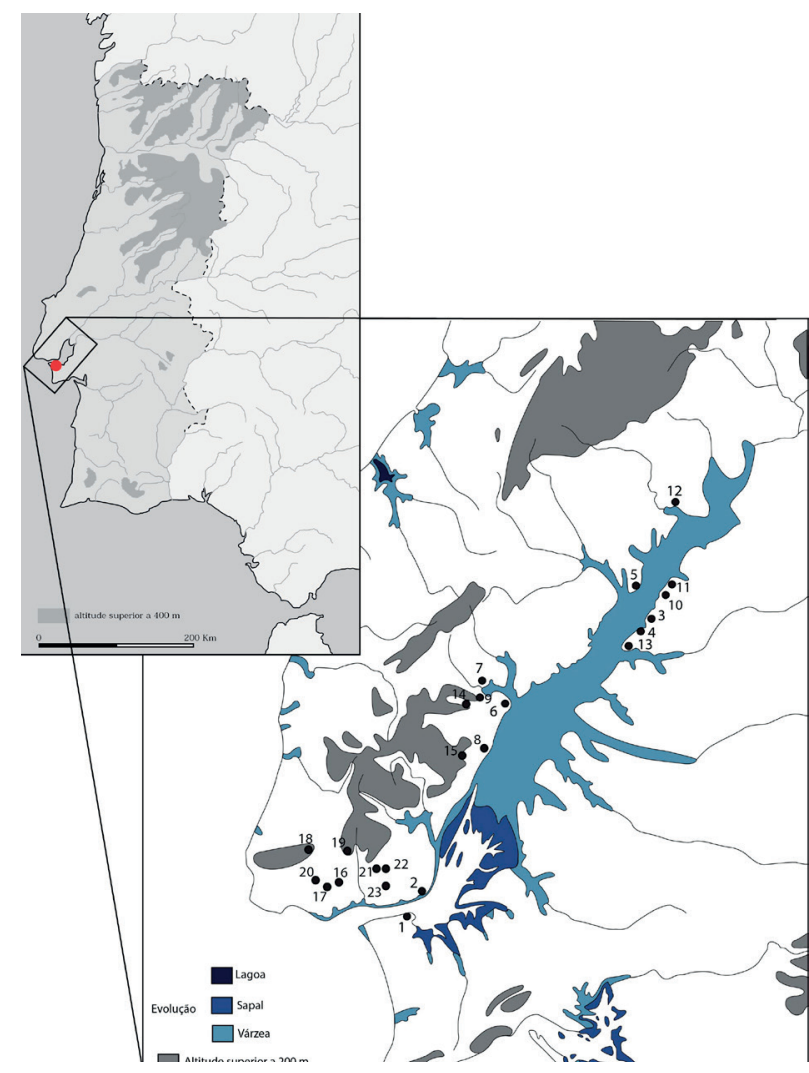

Figura 1 - Localização de Cacilhas no território actualmente português e povoamento do séc. VI a.C. no Estuário do Tejo. 1 - Quinta do Almaraz/Cacilhas; 2 - Lisboa; 3 - Alto dos Cacos; 4 - Porto do Sabugueiro; 5 - Santarém; 6 - Quinta da Marquesa; 7 - Castro do Amaral; 8 - Santa Sofia; 9 - Quinta da Carapinha; 10 - Cabeço da Bruxa; 11 - Alto do Castelo; 12 - Chões de Alpompé; 13 Eira da Alorna; 14 - Casal da Mó; 15 - Casal dos Pegos I; 16 - Leião; 17 - Freiria; 18 - Santa Eufémia; 19 - Baútas; 20 - Miroiço; 21 - Moinhos do Filipinho; 22 - Casal Vila Chã Sul; 23 - Outurela. (adaptado de Sousa 2014 Base cartográfica UNIARQ)

Posteriormente, entre 1987 e 1988, após a criação dos serviços Museológicos da CMA, o sítio foi alvo de uma escavação sistemática promovida pelo $\mathrm{Mu}-$ seu Municipal de Almada (Gomes e Antunes, 1986). A intervenção aconteceu no âmbito do projecto "Ocupação Romana na Margem Esquerda do Estuário do Rio Tejo", promovido pelas câmaras municipais de Almada, Alcochete, Seixal e Benavente, em colaboração com o CAA (Raposo, 2001, 50). No decorrer da referida intervenção (figura 2) foi possível reconhecer um conjunto de sete cetárias e dois tanques pequenos que, em conjunto com os artefactos recolhidos, permitiram um primeiro enquadramento cronológico do sítio, cuja ocupação romana 


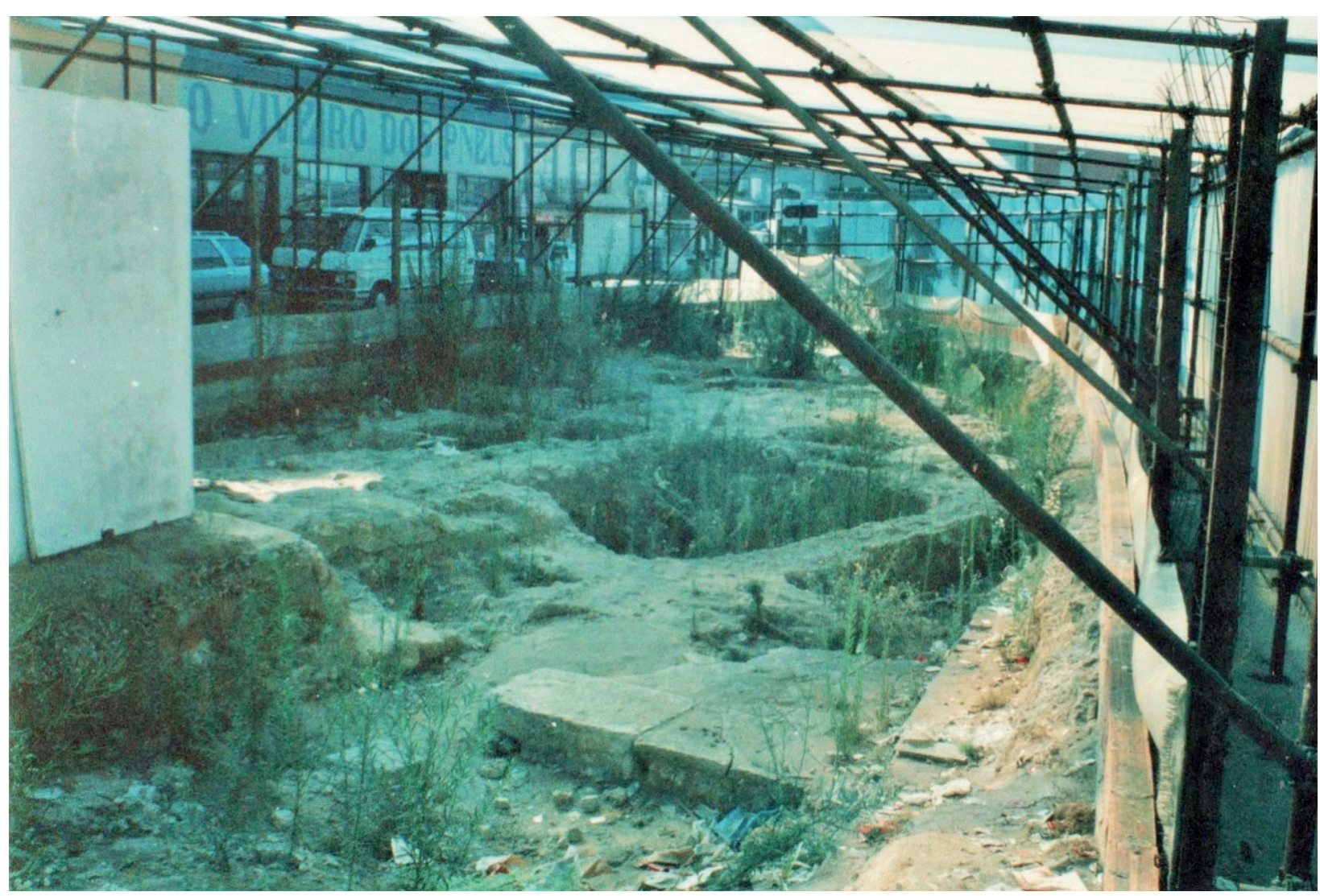

Figura 2 - Fotografia da área intervencionada entre 1987 e 1988 (“CAC”).

se enquadra genericamente entre o séc. I e o III d.C. (Barros e Henriques, 1998, 101; Bugalhão, 2001, 54).

Nesta intervenção foi ainda identificado, na área correspondente ao pátio da fábrica de salga, um muro "cujo aparelho [construtivo] diferia das paredes das cetárias", interpretado como "cais pré-romano" (Barros e Henriques, 1998, 101-102). Este (figura 3) assentava na rocha de base e apresentava vestígios de erosão fluvial até cerca de $1 \mathrm{~m}$ de altura. Junto a esta estrutura foram escavados três níveis distintos, no primeiro dos quais foi recolhido algum material cerâmico da Idade do Ferro associado, contudo, a cerâmica romana. Neste sentido, pelos dados que dispomos, cremos que não foram intervencionados quaisquer contextos preservados da Idade do Ferro nesta área de escavação, que incidiu, aparentemente, em depósitos secundários.

Em 1997, no decorrer de obras no interior do edifício da então Caixa Geral de Depósitos (CGD), foi realizada uma escavação de emergência, a qual revelou a existência de mais três cetárias e estruturas da Idade do Ferro. Estas estruturas (figura 4 ), compostas por muros de pedra seca de carac- terísticas análogas às identificadas na Quinta do Almaraz, definiam pelo menos um compartimento (denominado «Estrutura 1»), no interior do qual foram identificadas três camadas onde apenas se recolheram artefactos enquadráveis no $1^{0}$ milénio a.C.. A coerência cronológica dos materiais exumados nos referidos contextos leva-nos a considerar verosímil que sejam depósitos fiáveis, embora o parco registo de campo não o possa corroborar.

Pela importância dos vestígios arqueológicos identificados em Cacilhas, o sítio foi classificado na categoria de Imóvel de Interesse Público (Decreto-lei n. ${ }^{\circ}$ 26-A/92 de 1 de Junho).

O facto de a área de Cacilhas ter sido ocupada de forma intensa e ininterrupta desde o séc. XVI (Barros, Amaro, 1985, 34) até aos nossos dias, resultou numa complexa sobreposição de construções e utilização do espaço, deixando desta forma a maior parte da ocupação antiga afectada por revolvimentos recentes - em particular, a área da fábrica de salga romana. Apesar de se ter recolhido um apreciável conjunto de artefactos da 


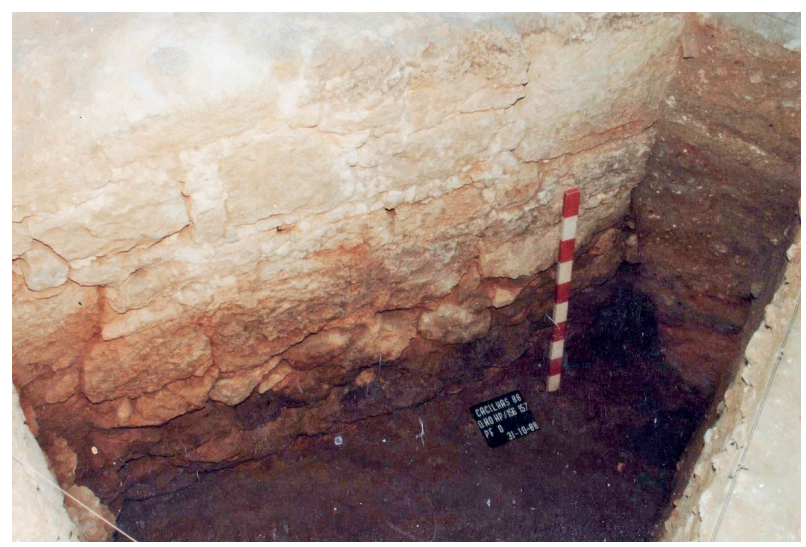

Figura 3 - Estrutura interpretada como cais pré-romano.

Idade do Ferro, os dados disponíveis não permitem uma análise pormenorizada dos contextos de proveniência. A presente abordagem, de carácter eminentemente tipológico, terá assim de ser observada à luz destas limitações.

\section{O CONJUNTO CERÂMICO}

$\mathrm{O}$ conjunto de materiais enquadráveis no $1^{0} \mathrm{mi}-$ lénio a.C. é composto por $75 \mathrm{NMI}$ provenientes de duas áreas distintas (figura 5). Das camadas associadas aos muros de pedra seca, área denominada "CAC II", foi recolhida a maioria do conjunto cerâmico, com 108 fragmentos classificáveis (62 NMI). $\mathrm{Da}$ área do pátio da fábrica de salga romana, denominados apenas como "CAC", foram recolhidos 16 fragmentos classificáveis (13 NMI), dos quais apenas um prato em cerâmica de engobe vermelho (CAC 45) e um pequeno fragmento de asa de cerâmica cinzenta se encontravam directamente associados à estrutura interpretada como "cais pré-romano» ( $\mathrm{K}$ 107), sendo os restantes provenientes da área contígua à estrutura (HO-HP/156-157).

\section{ÂNFORAS}

Os contentores anfóricos são elementos essenciais na caracterização das dinâmicas económicas e comerciais dos povoados e revelam-se igualmente importantes na determinação de cronologias para os contextos de recolha.

$\mathrm{O}$ conjunto anfórico da Idade do Ferro de $\mathrm{Ca}-$ cilhas conta com $10 \mathrm{NMI}$. Ainda que não se destaque pela sua expressividade quantitativa, revela-se bastante homogéneo a nível formal e cronológico. Distinguiram-se dois grupos de fabrico distintos, o primeiro dos quais (figura 6) de coloração alaranjada, com inclusões comuns de pequena e média dimensão

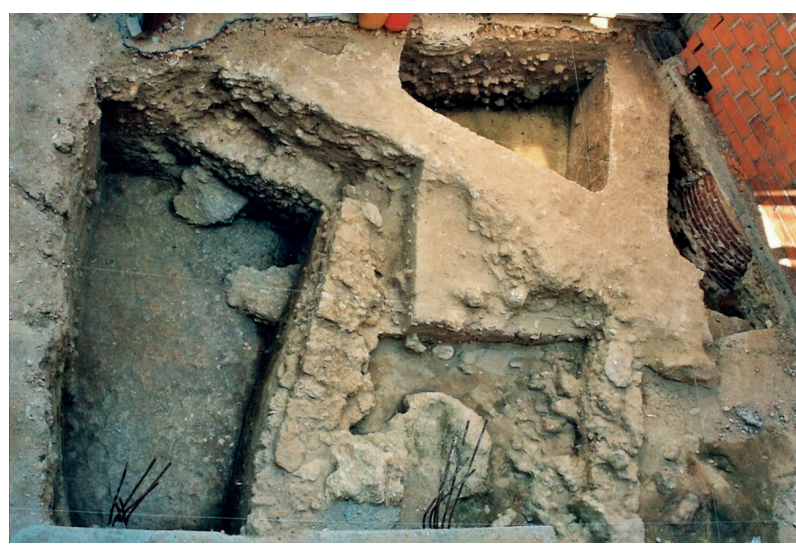

Figura 4 - Fotografia da área intervencionada em 1997, no interior da Caixa Geral de Depósitos ("CAC II"). Além das cetárias, constata-se a existência de muros de pedra seca, correspondentes a uma estrutura da Idade do Ferro.

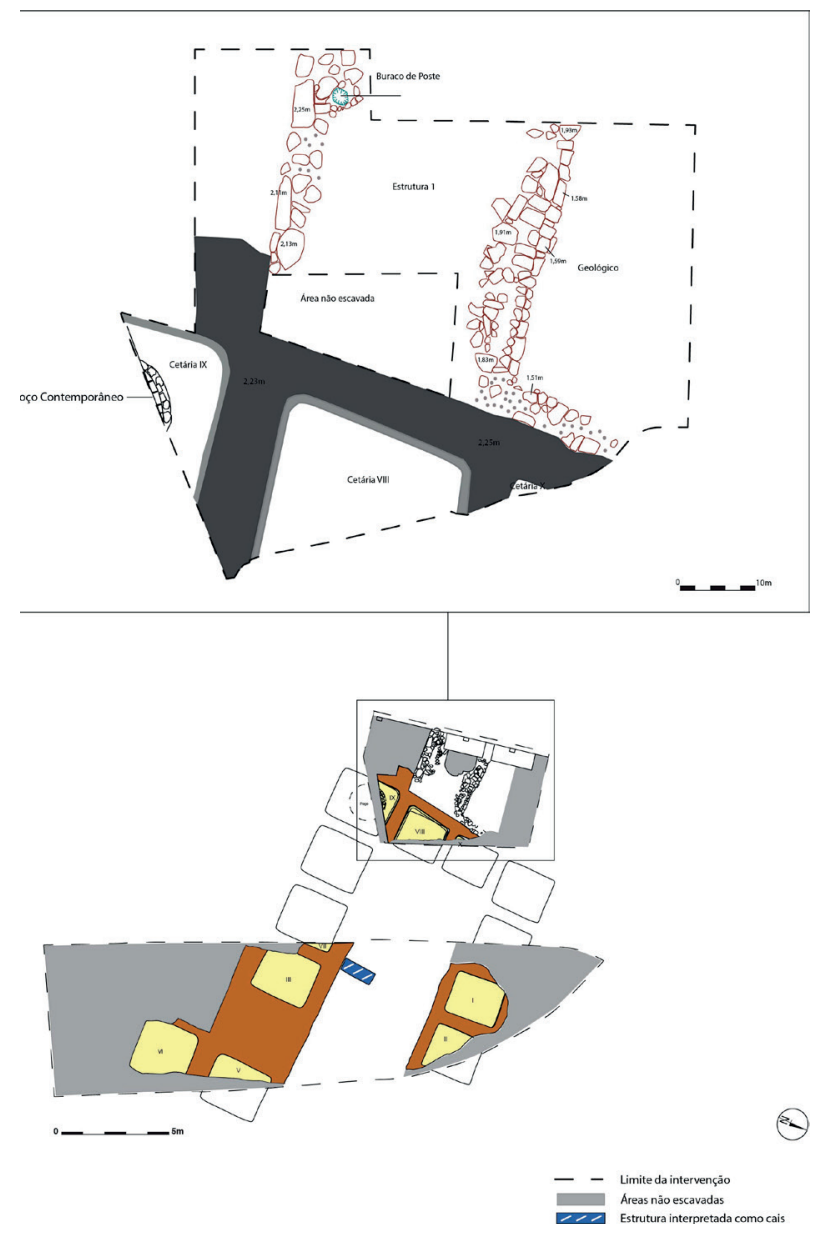

Figura 5 - Plano das áreas intervencionadas em Cacilhas com reconstituição possível da Fábrica de Salga de Peixe romana e pormenor das estruturas da Idade do Ferro. 


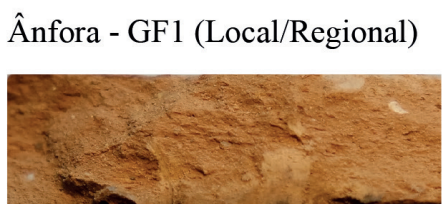

Pithoi - GF1 (Local/Regional)

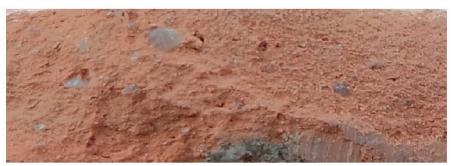

Cerâmica Pintada - GF1 (Local/Regional)

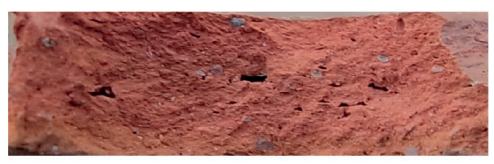

Engobe Vermelho - GF2 (Local/Regional)

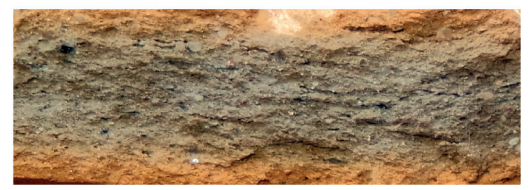

Cerâmica Cinzenta - GF2 (Local/Regional)

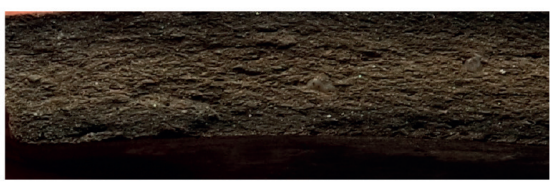

Cerâmica Comum - GF1 (Local/Regional)

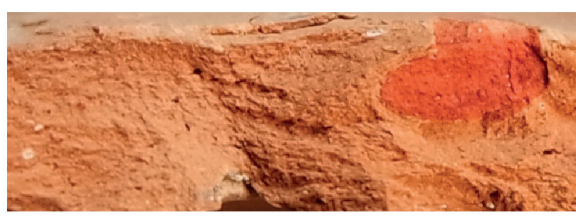

Cerâmica Comum- GF3 (Local/Regional)

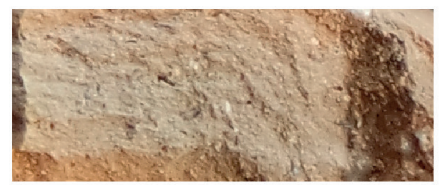

Ânfora - GF2 (Importação?)

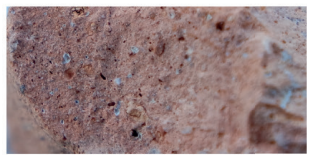

Cruz del Negro (Local/Regional)

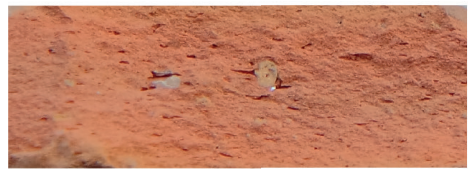

Engobe Vermelho - GF1 (Local/Regional)

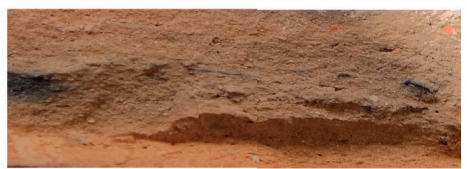

Cerâmica Cinzenta - GF1 (Local/Regional)

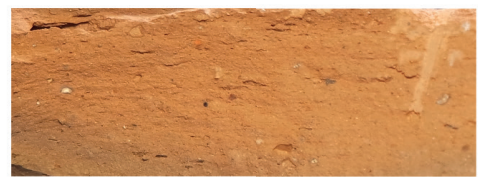

Cerâmica Cinzenta - GF3 (Local/Regional)

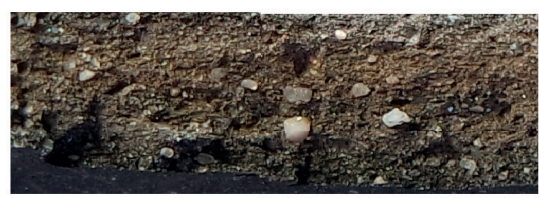

Cerâmica Comum- GF2 (Local/Regional)

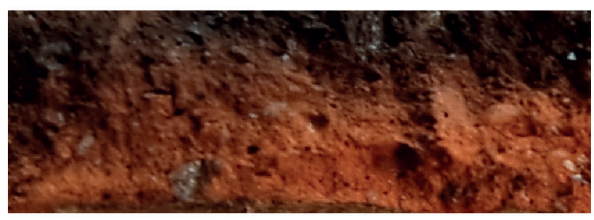

Cerâmica Manual- GF1 (Local/Regional)

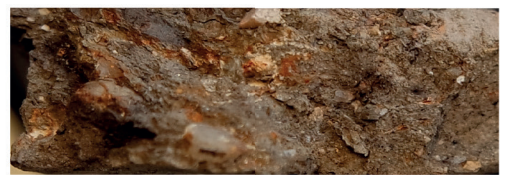

Figura 6 - Grupos de fabrico identificados. 
e um aspecto compacto e depurado. É neste grupo de fabrico que se enquadra a maioria do conjunto de ânforas em estudo (figura 7) e as suas características permitem associá-lo ao Grupo 1 do Estuário do Tejo, uma produção típica da área da foz deste rio (Sousa, Pimenta, 2014; Cardoso et al., 2017).

Os dados de Cacilhas contribuem assim para um avolumar de informação que confirma que a produção de ânforas no Estuário do Tejo, ao longo do $1^{0}$ milénio a.C., foi um fenómeno variado e complexo, com um desenvolvimento precoce. Como testemunha a presença de exemplares do Tipo 1 do Tejo num dos contextos mais antigos de Lisboa, a Rua São Mamede ao Caldas (Pimenta et al., 2014a, 729), a produção regional de ânforas teve início em algum momento entre os finais do século VIII e a primeira metade do séc. VII a.C., em cronologia tradicional, desenvolvendo-se ao longo de todo o milénio (Sousa e Pimenta, 2014, 305).

Apenas um indivíduo (CAC 37) apresenta um fabrico distinto, com uma pasta de coloração amarelada, abundantes inclusões de pequena e média dimensão e um aspecto compacto e depurado, para o qual se apontou uma provável origem no Sul da Península Ibérica (figura 6). Poderá assim corresponder a um exemplar do tipo 10.1.2.1. de Ramon Torres importado, eventualmente da área de Cádis ou do seu entorno geológico.

A nível morfológico, o conjunto de Cacilhas é composto, sobretudo, por exemplares do Tipo 1 do Tejo. Este é também o tipo mais representado na Quinta do Almaraz, sítio em que corresponde a $55 \%$ do conjunto de bordos (Olaio, 2018).

Entre os exemplares de Cacilhas, três indivíduos apresentam bordos verticais e as paredes a desenvolverem-se de forma consideravelmente horizontal a partir do bordo, anunciando uma morfologia ovóide (CACII 35, 45 e 112) - características comuns em modelos produzidos até ao final do séc. VI a.C. (Olaio, 2018). Os restantes exemplares apresentam paredes muito mais pendentes e bordos exvertidos, com amplitudes de diâmetro consideráveis, elementos típicos de exemplares mais tardios (Sousa e Pimenta, 2014), que parecem surgir essencialmente a partir do final do séc. VI a.C. em diante (Olaio, 2018). Um outro fragmento integra-se no tipo 3 do Tejo (CAC 59), cujo início de produção ocorre presumivelmente em meados ou finais do séc. VI a.C., perdurando pela centúria seguinte (Sousa e Pimenta, 2014; Sousa, 2016). Este é o tipo com maior representação na Quinta do Almaraz a seguir ao tipo 1 do Tejo, num total de $27 \%$ do conjunto de bordos (Olaio, 2018). Por fim, sem possibilidade de atribuição a uma forma específica, deve referir-se a recolha de um bojo com carena bem evidenciada e duas asas de rolo de secção circular.

\section{PithoI}

Em Cacilhas estão representadas as formas de cerâmica pintada em bandas mais frequentes do mundo de influência fenícia no ocidente, concretamente os pithoi e as urnas de tipo Cruz del Negro.

Os pithoi, em particular, estão representados no conjunto por 5 NMI (figura 8), ostentando características de fabrico afins ao GF1 definido para o conjunto de ânforas, que remete invariavelmente para uma produção local/regional (figura 6).

No conjunto cerâmico de Cacilhas evidenciam-se alguns fragmentos de asas bífidas e bojos pintados em bandas bícromas (vermelhas e negras) ou polícromas (vermelhas, negras e brancas) horizontais, possivelmente pertencentes a pithoi (figura 9). Além destes, foram recolhidos cinco fragmentos de bordo (figura 8), tendencialmente exvasados e ligeiramente pendentes, com um perfil triangular e lábio pintado, interna e externamente, a vermelho. Apresentam igualmente um colo bitroncocónico, de paredes côncavas, separado do corpo por um ressalto bem marcado a toda a volta e, em dois casos (CACII 38 e 64), conservaram-se vestígios de uma asa bífida que arranca do bordo. Apresentam grandes afinidades com alguns exemplares de Santarém, em particular aqueles que se enquadram nos estratos médios, da segunda metade do séc. VII ao final do séc. VI a.C. (Arruda, 1999/2000, 192), o que coincide com o momento em que estes recipientes surgem de forma mais abundante nos contextos de Lisboa (Sousa, 2016, 176).

Dois fragmentos de pithoi apresentam a canelura que separa o colo do corpo das peças bem definida (CAC 73, CACII 76), característica que tem sido associada a exemplares com cronologias centradas no século VII a.C. (Torres Ortiz, 2002, 150). No entanto, parece-nos que devem ser matizados os dados de evolução morfológica dos pithoi, principalmente, quando baseados em artefactos exógenos. $\mathrm{O}$ avolumar de dados bem estratigrafados no Estuário do Tejo permitirá, com o desenvolvimento da investigação, que se elabore um quadro morfológico das produções desta região.

\section{URNA TIPo CRUZ DEL Negro}

As urnas tipo Cruz del Negro correspondem a recipientes fechados, de forma globular ou ovóide, 

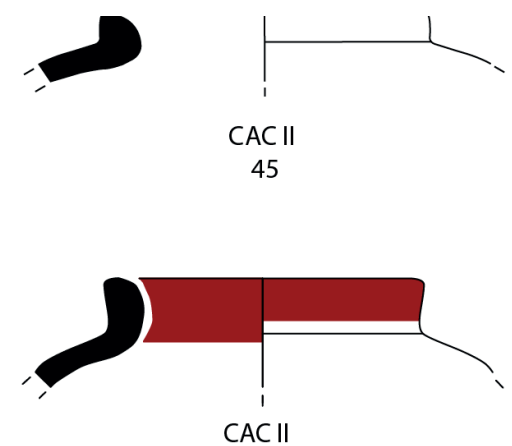

35
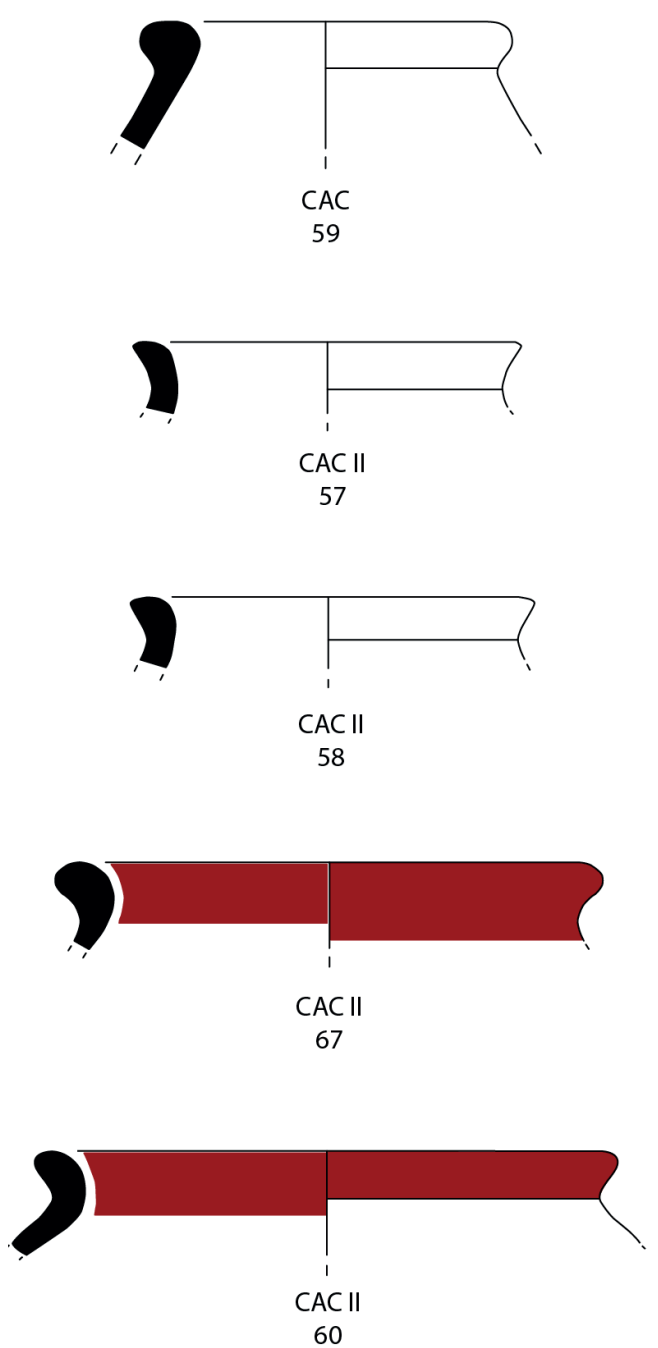

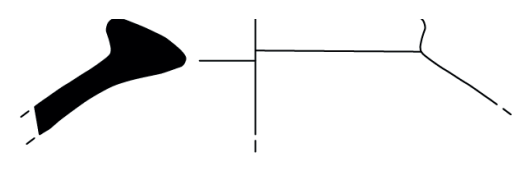

CAC II

112

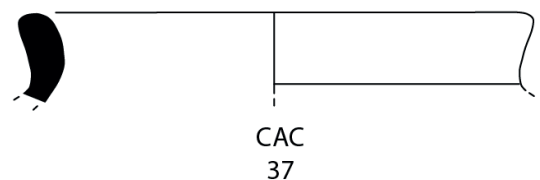

37

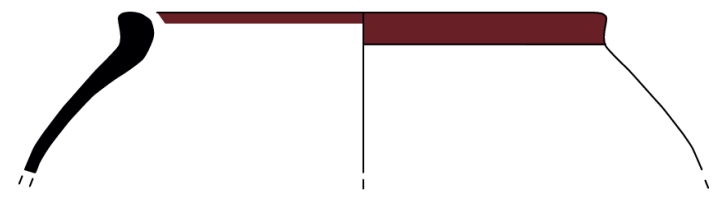

CAC II

11
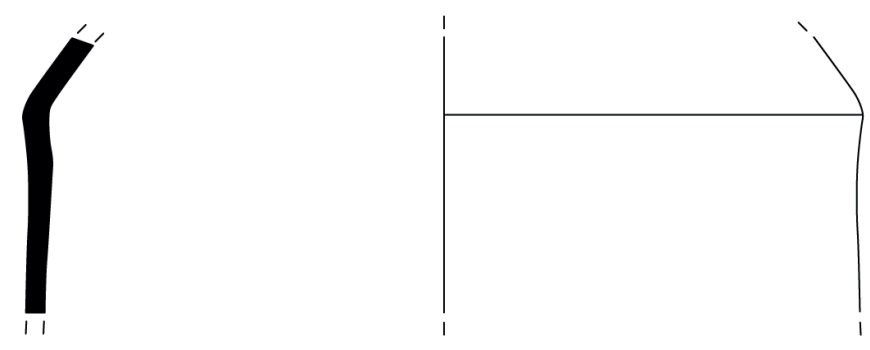

CAC
62
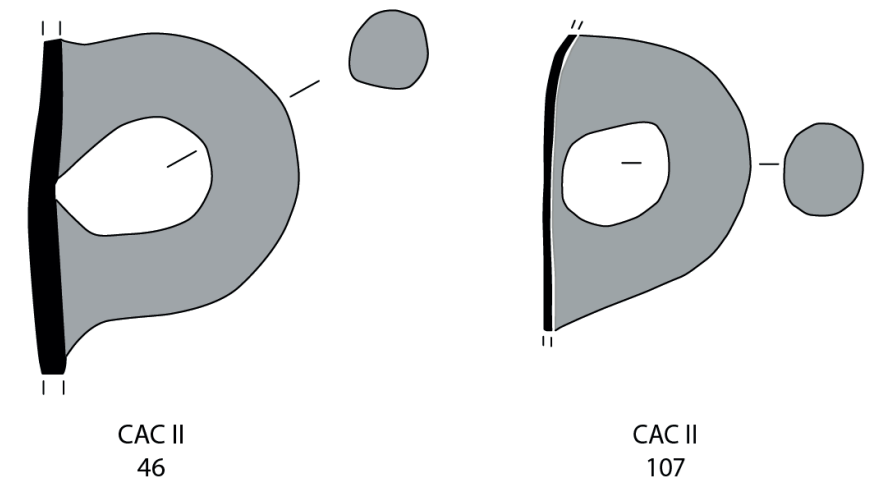

CAC I

107

Figura 7 - Ânforas. 

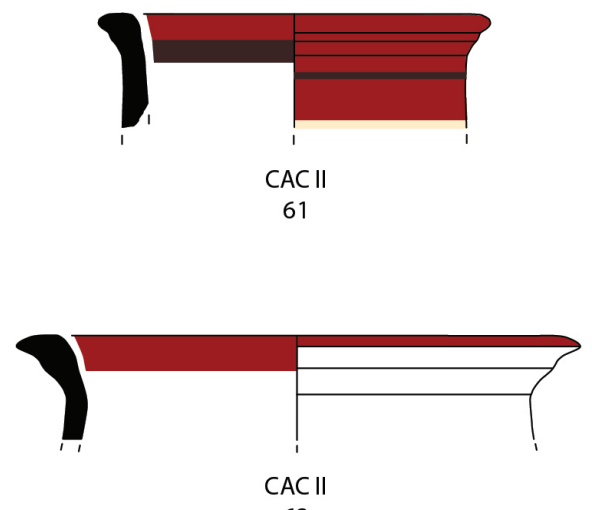

62

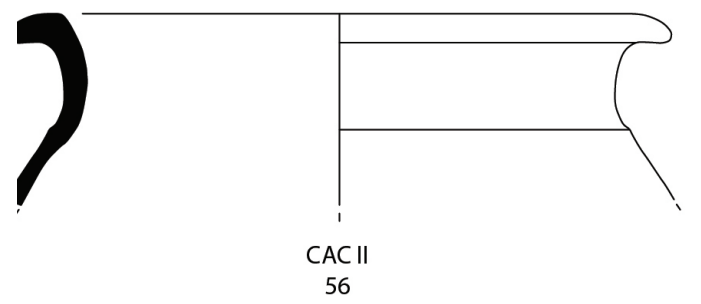

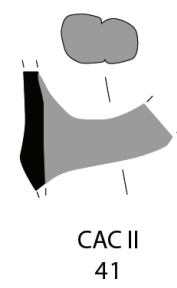

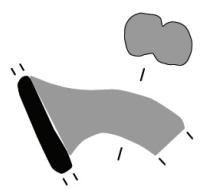

CAC II

111

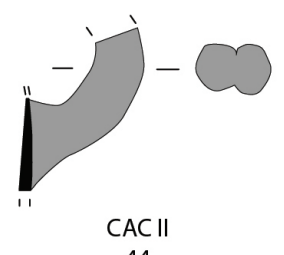

44

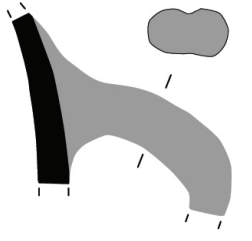

CAC II

43

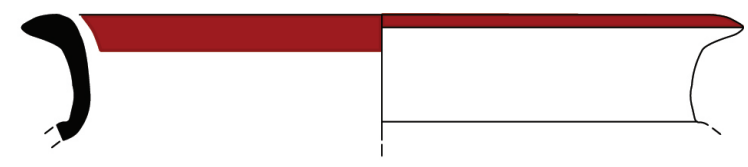

CAC

73

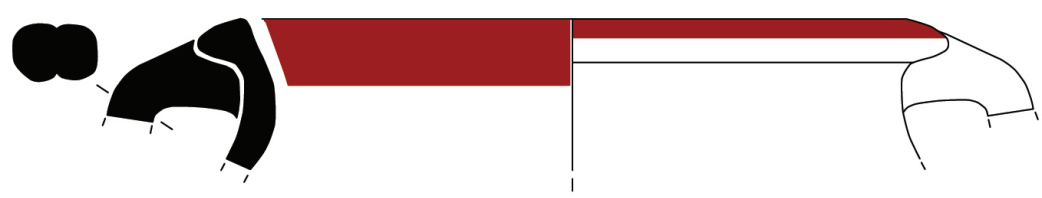

38

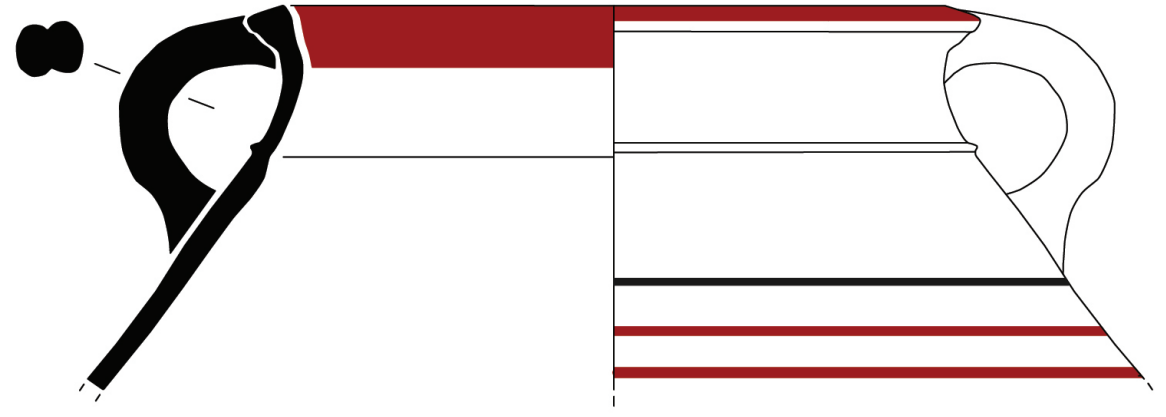

CAC II

64

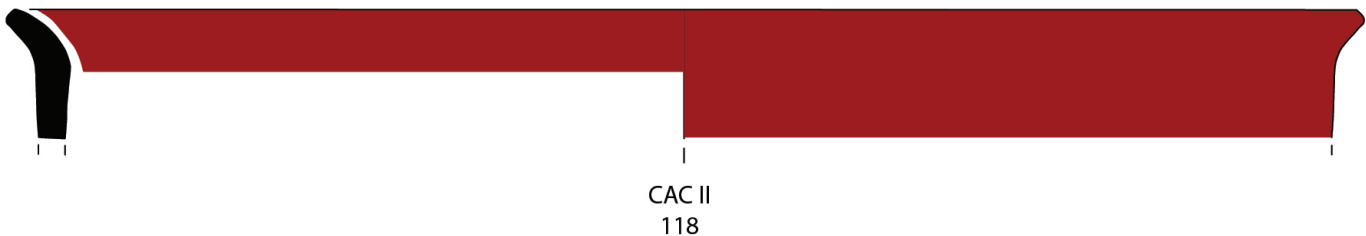

Figura 8 - Urna tipo Cruz del Negro (CAC II 61), Cerâmica pintada (CAC II 118) e Pithoi. 

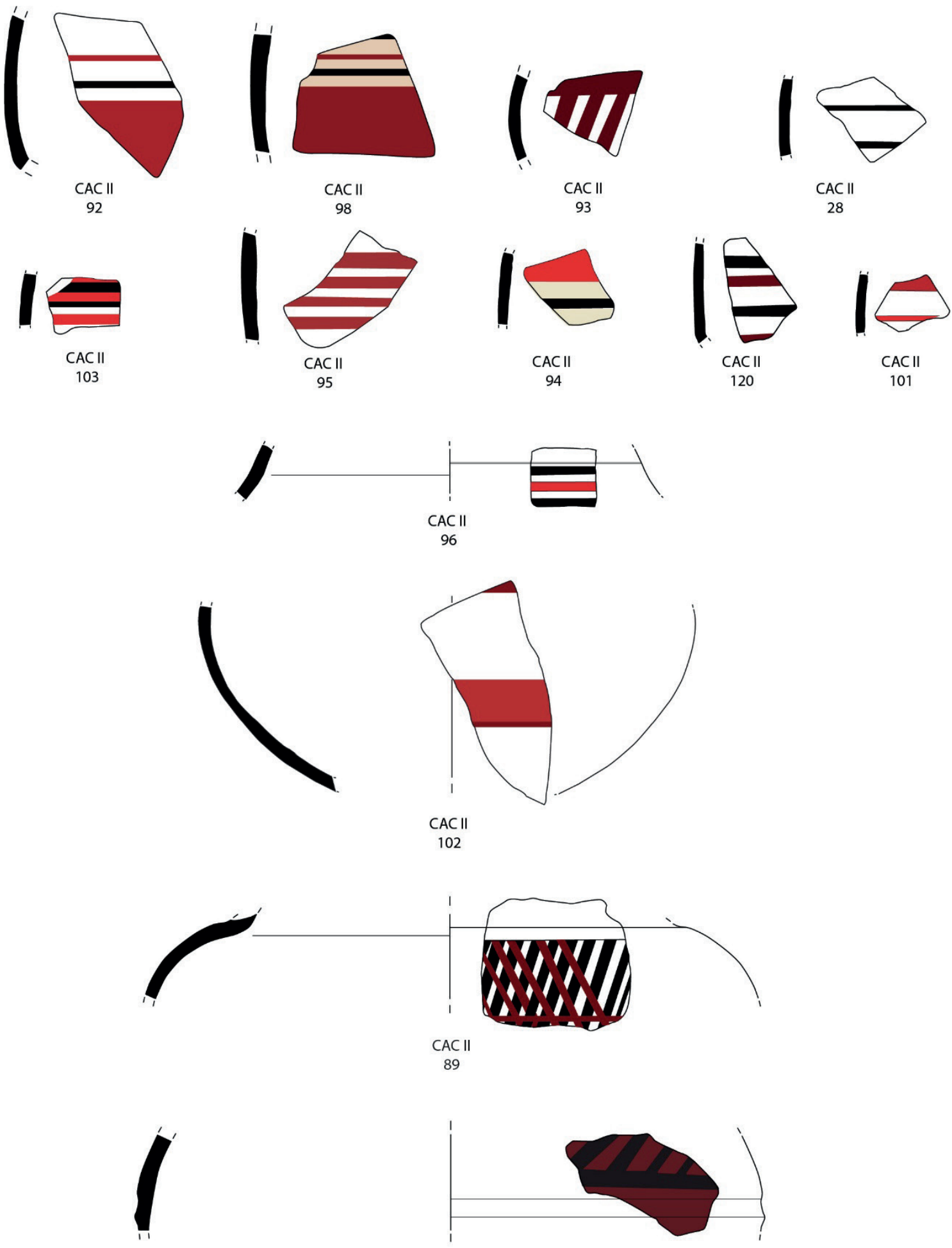

CACII

97

Figura 9 - Cerâmica pintada e urna Cruz del Negro (CACII 89) 
com colo cilíndrico ou troncocónico, que apresentam um pequeno ressalto em redor do colo a partir do qual partem duas asas bífidas que se juntam ao ombro da urna. Cronologicamente, encontram-se ao longo de toda a primeira metade do $1^{0}$ milénio a.C., registando-se em Lisboa em estratos datados entre os finais do século VIII e os finais do VII a.C. (Fernandes et al., 2013; Pimenta et al., 2014a, 728). Não obstante, na área do Sado, concretamente em Abul e na necrópole do Olival do Senhor do Mártires, alcançam o século VI e, inclusive, o V a.C., sendo que, na necrópole do Olival do Senhor dos Mártires, um dos exemplares é de produção manual (Paixão, 1970; Frakenstein, 1997; Mayet e Silva, 2000).

O único exemplar de bordo presente no conjunto de Cacilhas (figura 8), com características de fabrico igualmente integráveis no Grupo 1 do Estuário do Tejo (figura 6), corresponde a um fragmento de bordo e colo de tendência vertical, pintado interna e externamente - características que, infelizmente, não possibilitam tecer grandes considerações sobre o enquadramento da peça nas tipologias existentes. Não obstante, refere-se uma das conclusões de Diego Ruiz Mata que assinala que os exemplares mais recentes possuem colos mais abertos e inclinados (Ruiz Mata, 1987 apud Torres Ortiz, 2008, 635) destacando-se aqui, por oposição, a verticalidade do exemplar de Cacilhas.

Também um dos fragmentos de bojo poderá corresponder a uma urna de tipo Cruz del Negro visto que ostenta um corpo globular e o arranque para o colo (figura 9: CACII 89). Esta peça apresenta a parede externa pintada em bandas negras e vermelhas oblíquas cruzadas, com uma banda vermelha recta no fundo. Os dois exemplares exibem características técnicas que consideramos que podem ser provenientes de ateliers regionais, algo que não é inédito visto que, para os fragmentos identificados no Pátio do Aljube, em Lisboa, foi também apontada uma origem regional (Fernandes et al., 2013, 181).

\section{CERÂMICA DE ENGOBE VERMELHO}

A cerâmica de engobe vermelho é introduzida nos repertórios do Baixo Tejo com uma aparentemente rápida afirmação de uma produção regional do tipo cerâmico, atestada desde as fases mais antigas da influência fenícia no Estuário do Tejo até momentos mais tardios do séc. IV a.C. (Pimenta et al., 2014a, 725-735; Sousa, 2014, 114-129).

Em Cacilhas encontra-se representada por 17 NMI, distinguindo-se dois grupos de fabrico dis- tintos (figura 6), o primeiro dos quais de características análogas ao Grupo 1 do Estuário do Tejo. O segundo grupo de fabrico, ao qual também atribuímos uma origem local/regional, apresenta uma coloração que varia entre o castanho alaranjado e o cinzento, com inclusões comuns de pequena e média dimensão e um aspecto compacto, medianamente depurado e algo arenoso, está representado por apenas um fragmento (CACII 73).

A maioria do conjunto corresponde a pratos de bordo contínuo (figura 10), praticamente indiferenciável da parede e de tendência aplanada. Apresentam grandes afinidades com a forma P3 que Rufete Tomico definiu para a área de Huelva (Rufete Tomico, 1988-1989, 17), onde surge entre os meados do séc. VII a.C. e os meados do VI a.C.; bem como com a forma 4 de Medellín, que se regista em contextos datados entre os finais do séc. VII a.C. e os meados do VI a.C. (Almagro-Gorbea et al., 2008, 606-607). Este é um tipo de prato comum nos repertórios do Estuário do Tejo, onde se documenta, também, desde o séc. VII a.C. até meados do $1^{0}$ milénio a.C. (Sousa, 2014, 121-122). Refira-se ainda a presença da forma na Quinta do Almaraz, onde foi identificada em conjunto com modelos mais arcaicos (Barros et al., 1993, 177-178).

Um dos exemplares apresenta um lábio biselado (Fig. 10: CACII 39), característica com paralelos na Casa dos Bicos (Pimenta et al., 2015, 168) e na forma II.B.3 definida para o engobe vermelho de Castro Marim, onde surge apenas na Fase III, cuja cronologia se enquadra no séc. VII a.C. (Freitas, 2005, 31 e 52).

Estão igualmente presentes, em Cacilhas, taças carenadas afins ao tipo C3 de Rufete Tomico (figura 10: CACII 24, 70 e 71), igualmente presentes em Almaraz, mormente, nas taças carenadas do tipo B do sítio (Barros et al., 1993, 179). Este tipo de taças encontra-se datado, em Lisboa, entre os séculos VII e VI a.C. (Sousa, 2016, 173-174), estando ausentes de contextos do V a.C. em diante, como é o caso da Rua dos Correiros (Sousa, 2014, 128).

Devemos por fim salientar que a totalidade dos fragmentos de cerâmica de engobe vermelho analisados corresponde a produções que consideramos de origem local/regional, situação similar a diversos contextos identificados em Lisboa (Arruda, 19992000; Pimenta et al., 2014a; Sousa, 2014) e Santarém (Arruda, 1999-2000). Estes dados indiciam a existência de um ou vários centros produtores que abasteceriam os sítios do Estuário do Tejo, tal 

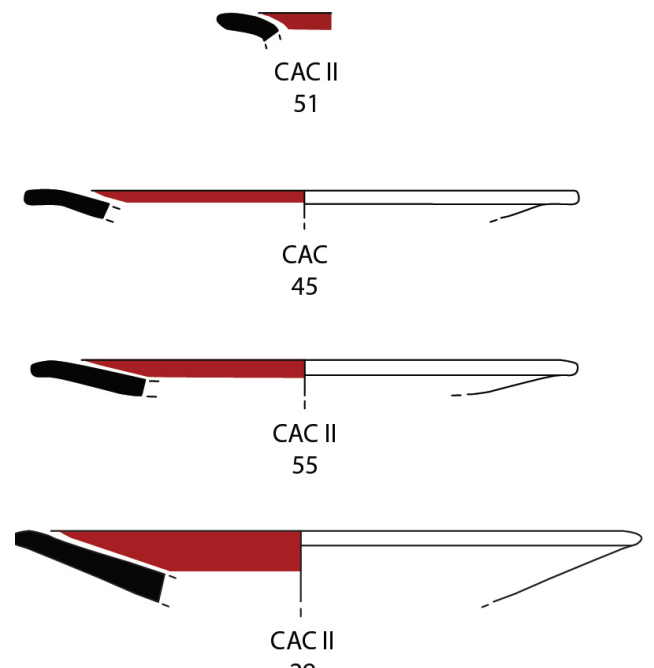

29

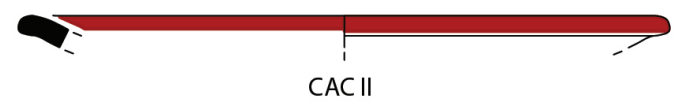

25
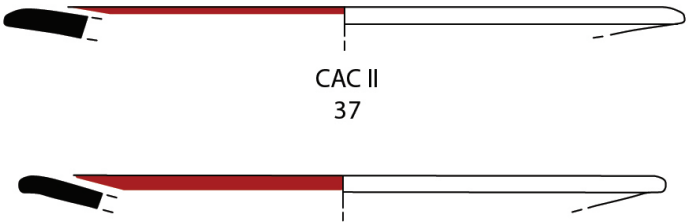

CAC II

54

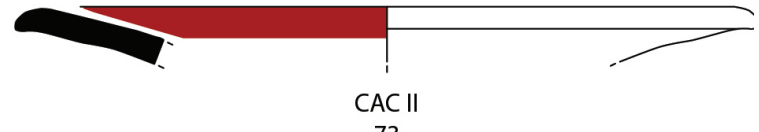

73
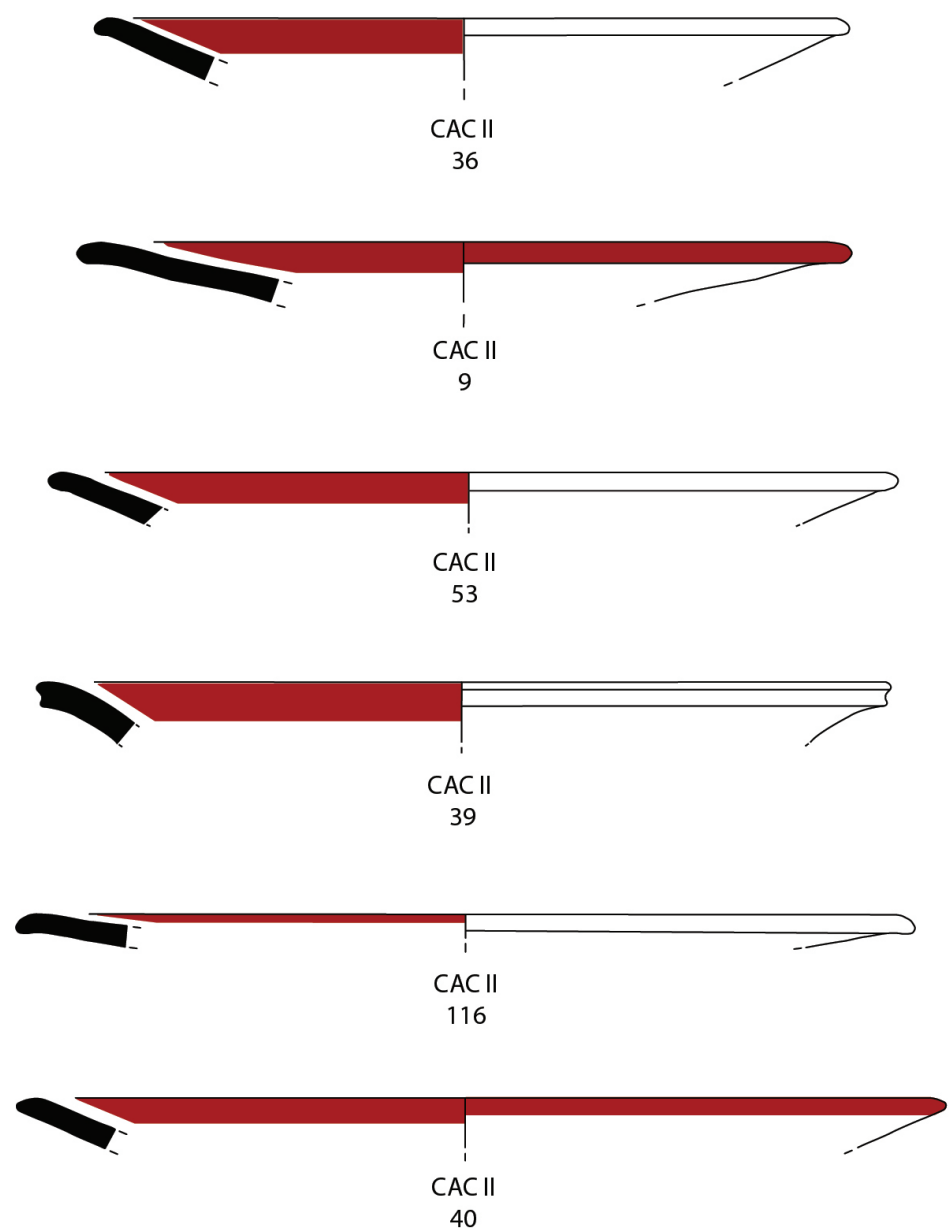

$10 \mathrm{~cm}$

Figura 10 - Cerâmica de engobe vermelho. 

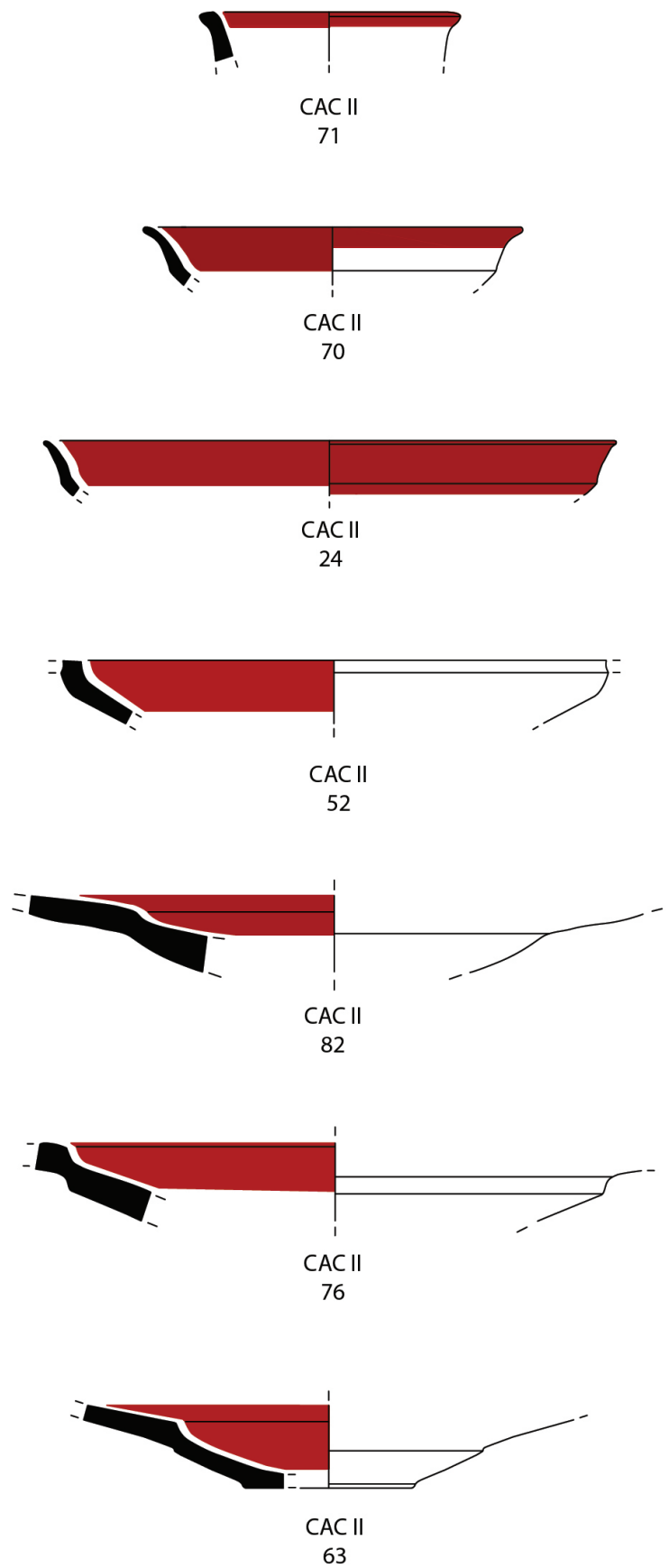

63
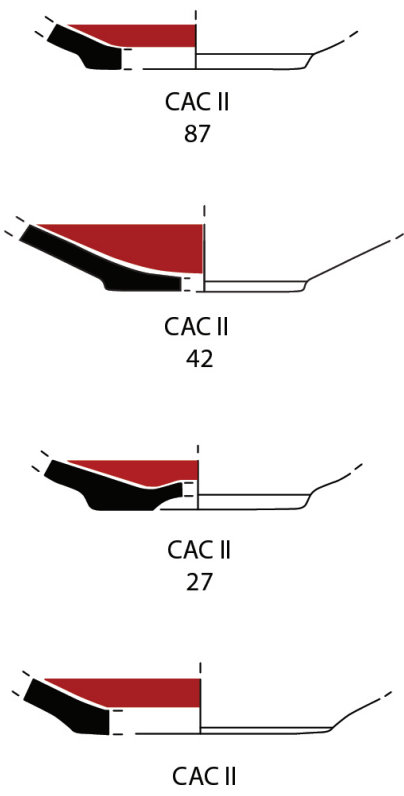

83
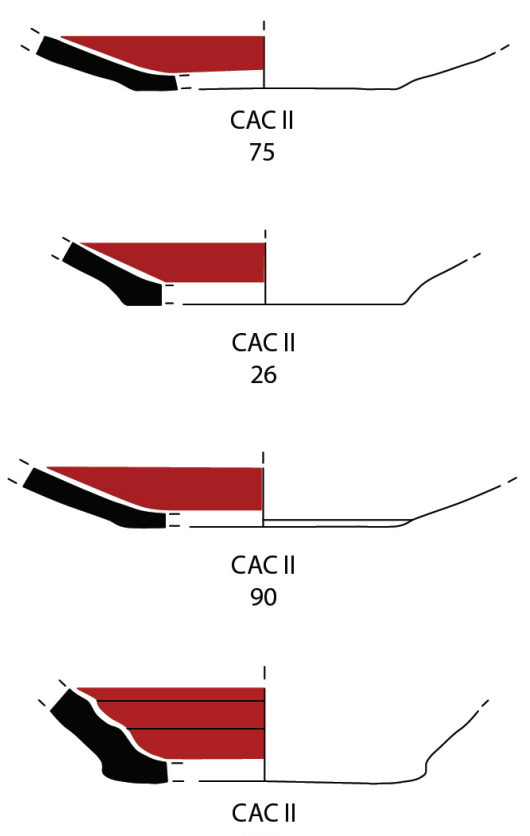

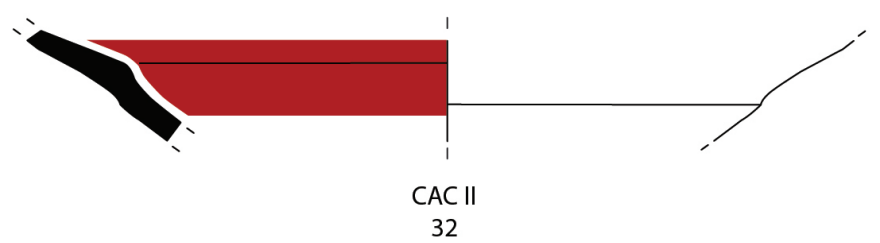

$10 \mathrm{~cm}$

Figura 11 - Cerâmica de engobe vermelho. 

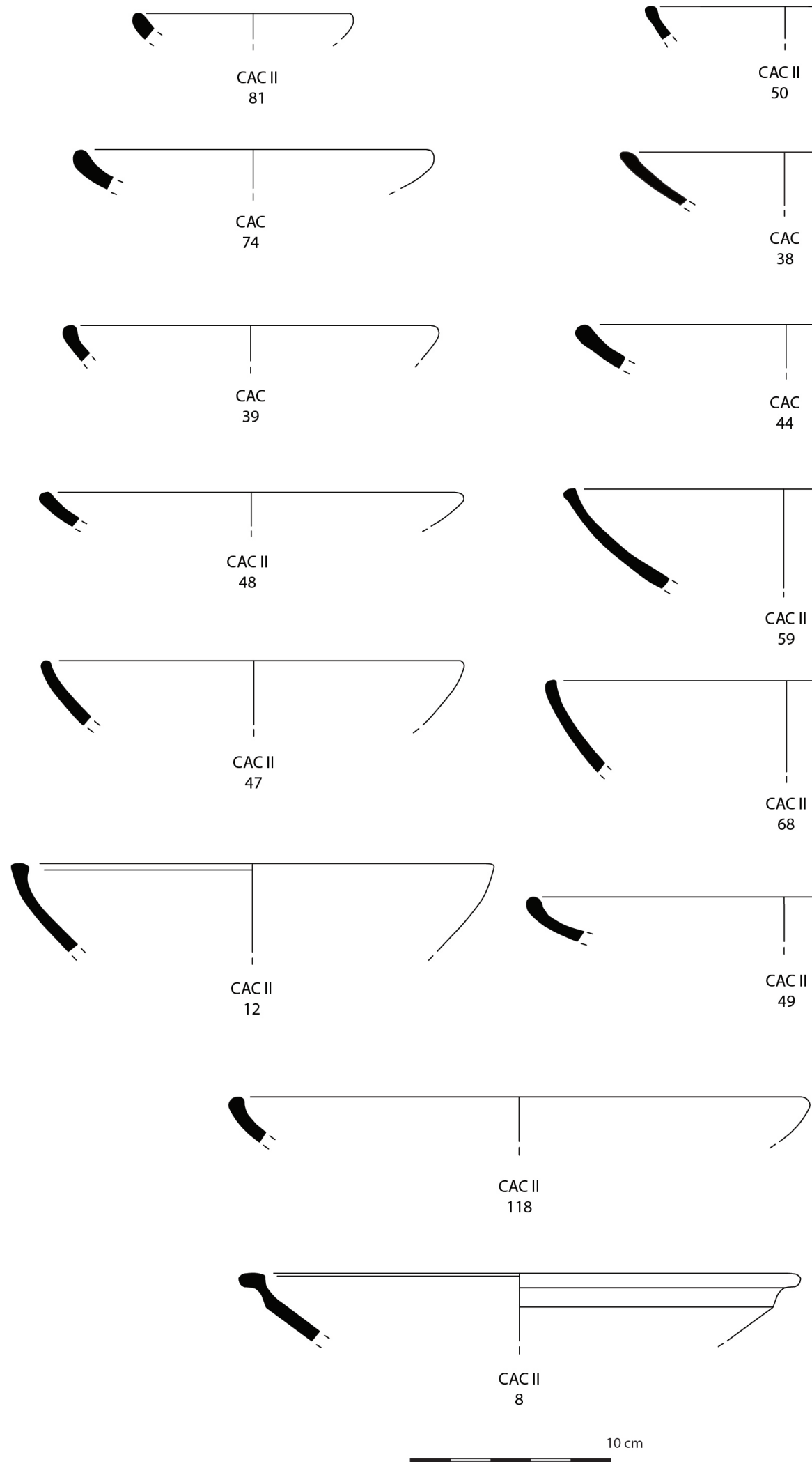
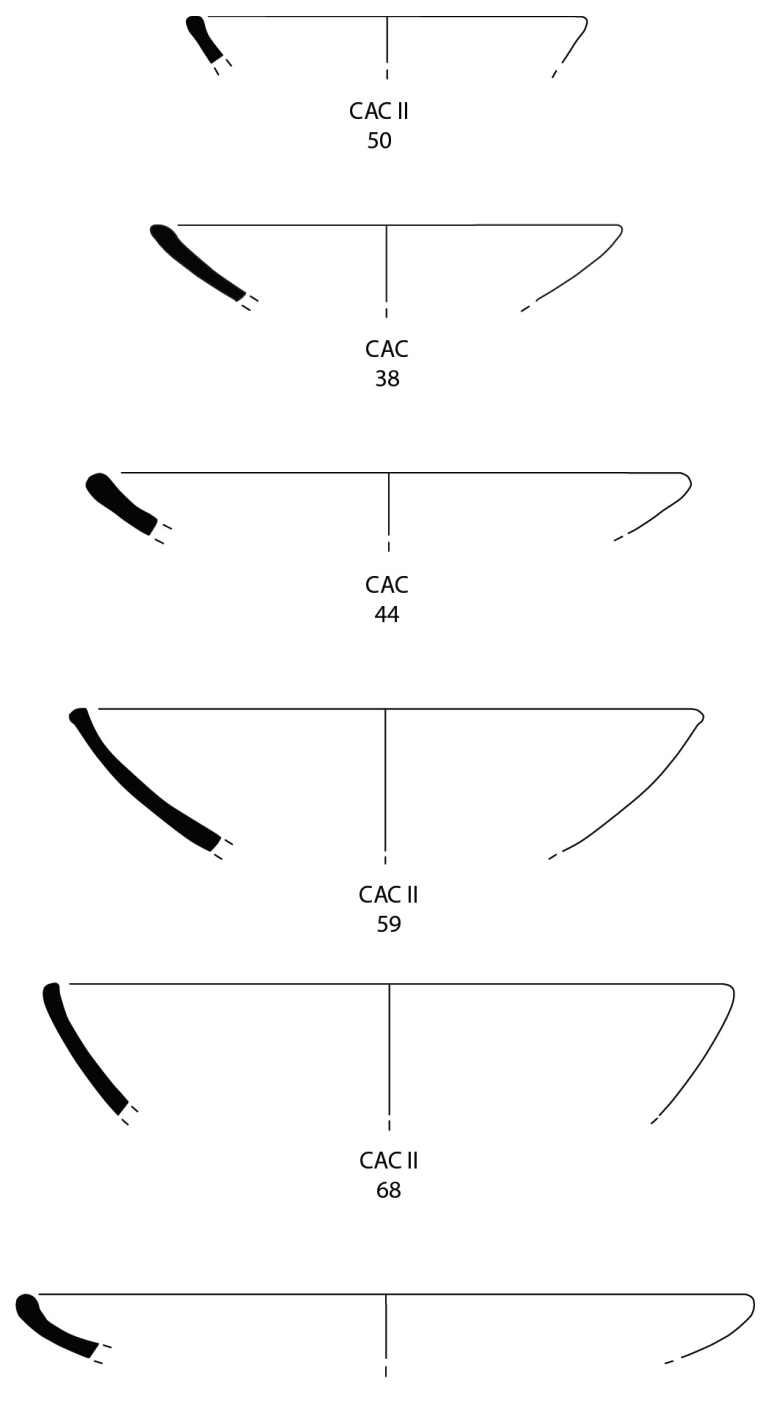

CAC II
49

Figura 12 - Cerâmica cinzenta. 


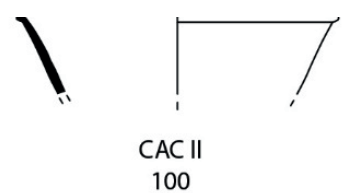

1

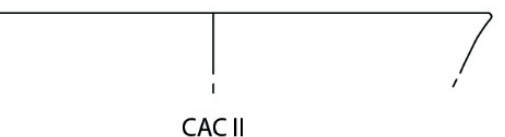

69

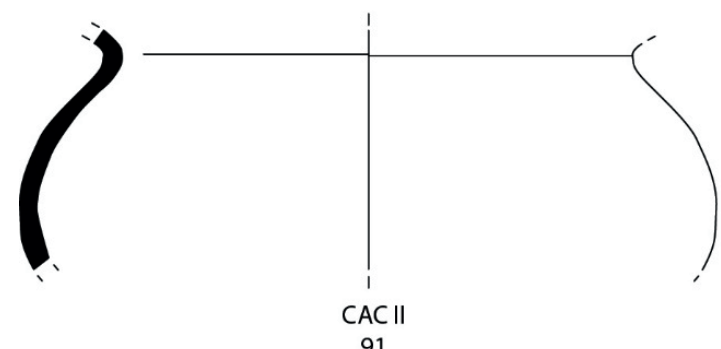

91

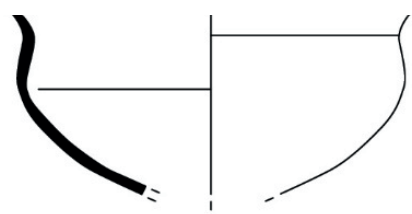

CAC II

10

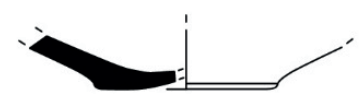

CACII
78

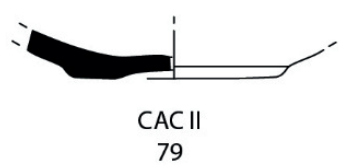

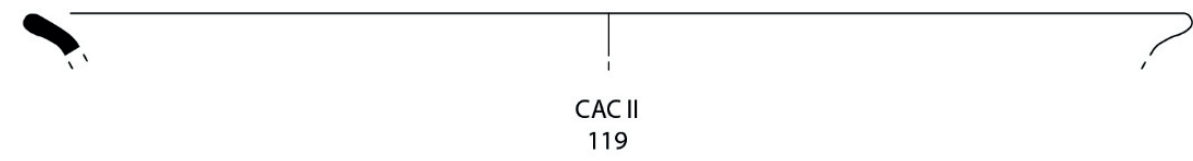
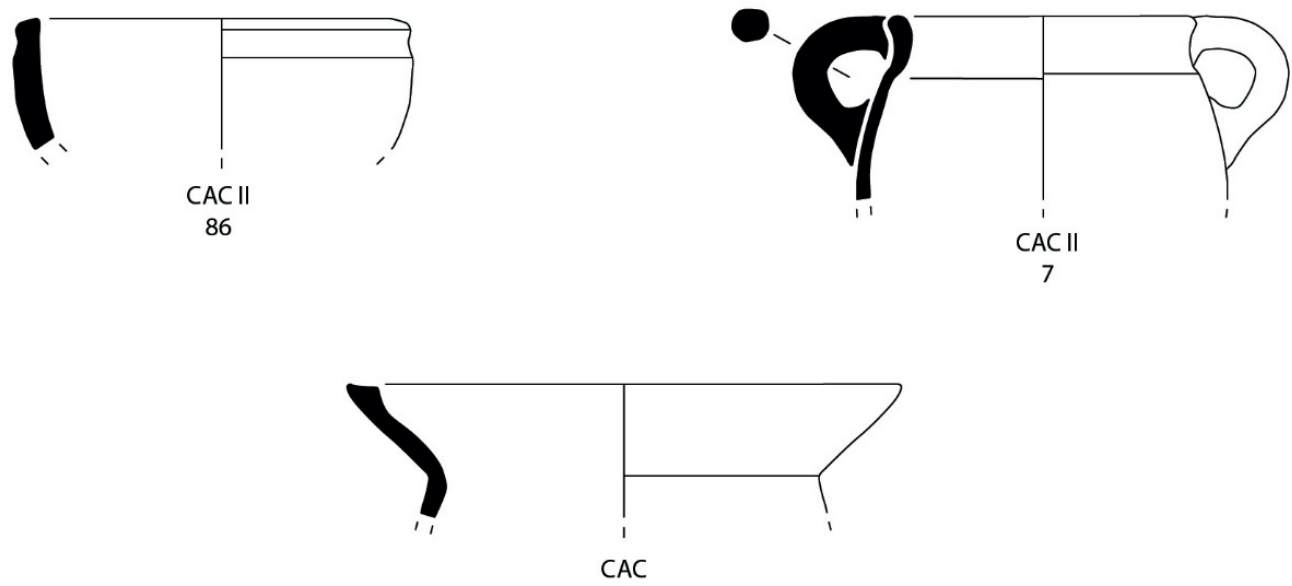

64

$10 \mathrm{~cm}$

Figura 13 - Cerâmica cinzenta (CAC II 100, 69, 91, 10, 78, 79, 119) e cerâmica comum (CAC II 86, CAC II 7, CAC 64). 
como proposto por Ana Margarida Arruda (Arruda, 1999-2000, 120; Arruda, 2014, 525).

\section{Cerâmica cinzenta (figura 11)}

A cerâmica cinzenta surge de forma expressiva em contextos da primeira metade do $1^{0}$ milénio a.C. e, apesar de se registar até ao início do período romano, vai perdendo significado quantitativo nos conjuntos a partir de meados do milénio. No conjunto de Cacilhas, esta categoria encontra-se bem representada, com 18 NMI.

Distinguiram-se três grupos de fabrico (figura 6), todos de provável origem local/regional. O primeiro enquadra-se no Grupo 1 do Estuário do Tejo e é o mais representado, com quase metade dos exemplares. Segue-se o grupo de fabrico 2 que apresenta uma coloração entre o cinzento-claro e o cinzento-escuro, com inclusões comuns de pequena dimensão e um aspecto compacto e depurado. Por fim, o grupo de fabrico 3 distingue-se do anterior por apresentar abundantes inclusões de média e grande dimensão e um aspecto menos depurado.

A nível formal, a maioria dos exemplares corresponde a taças de perfil hemisférico, genericamente enquadráveis no tipo 1 da Sé de Lisboa (figura 12) (Arruda et al., 2000). É uma forma típica de contextos da Idade do Ferro na Península Ibérica, que surge no séc. VII a.C. e, no Tejo, perdura até atingir o período romano (Arruda, 1999/2000, 196; Sousa, 2016, 182). Apesar da variante $1 \mathrm{~A}$ definida para a Sé de Lisboa ser a mais representada no conjunto de Cacilhas, com um total de sete indivíduos, verificam-se ainda cinco exemplares da variante $1 \mathrm{~B}$ (figura 12: CAC 39, CACII 12, 49, 50 e 118) e um enquadrável na variante $1 \mathrm{C}$ (figura 12: CAC 38).

Tendo em consideração a frequência com que esta forma surge em contextos do $1^{0}$ milénio a.C., considera-se desnecessária uma exposição exaustiva dos paralelos, mencionando-se apenas que a variante $1 \mathrm{~A}$ da Sé de Lisboa tem correspondência no tipo 1A definido para a Quinta do Almaraz e é também a forma predominante no conjunto estudado deste povoado (Henriques, 2006).

Além destes, estão presentes dois potes com um corpo de tendência globular e um perfil em S (figura 13: CACII 10 e 91), que recordam modelos anteriores à Idade do Ferro e encontram paralelos no tipo $3 \mathrm{da}$ Sé de Lisboa (Arruda et al., 2000, 32). Tendo em consideração a sua ausência em contextos do séc. $\mathrm{V}$ a.C. em diante, foi considerada como uma forma típica do séc. VI a.C. (Sousa, 2014, 144).
O mesmo acontece com o exemplar de prato de bordo horizontal e aplanado (figura 12: CACII 8), com paralelo no tipo 2 da Sé de Lisboa (Arruda et al., 2000: 32), forma que parece inspirar-se em modelos de pratos de engobe vermelho (Arruda, 1999/2000, 199) - como, aliás, se comprova pela existência de um exemplar desta forma, em cerâmica de engobe vermelho, no próprio Almaraz (Barros e Henriques, 2002, 308). O prato de bordo horizontal aplanado é uma forma que surge apenas na fase II (séc. VII/VI a.C.) definida por Elisa de Sousa para o Estuário do Tejo (Sousa, 2016, 176), estando, para já, ausente de sítios com cronologias do séc. V a.C. em diante (Sousa, 2014, 144).

Registam-se ainda dois fragmentos (figura 13: CACII 69 e 100) de bordo com colo alto, que poderão corresponder a potes, ainda que o estado de fragmentação não permita uma identificação segura. Apresentam afinidades com várias formas, nomeadamente com o tipo 3C da Sé de Lisboa (Arru$\mathrm{da}$, et al., 2000, 41) e com as variantes $3 \mathrm{Ba}$ e $4 \mathrm{Aa}$ definidas para a Rua dos Correeiros (Sousa, 2014, 140-141). Para além destes, encontram paralelos em diversos sítios do estuário com cronologias entre os finais do séc. VI e o IV a.C.. Um último fragmento de bordo de cerâmica cinzenta (figura 13: CACII 119), pela sua exiguidade, não permite grandes ilacções. Porém, registam-se as afinidades com a forma 4Ca da Rua dos Correeiros (Sousa, 2014, 142-143).

Por fim, mencionam-se os dois fundos (figura 13), que se apresentam ligeiramente destacados e côncavos, características típicas de várias formas de cerâmica cinzenta.

\section{CERÂMica Comum}

A cerâmica comum está atestada em Cacilhas por 20 fragmentos (17 NMI). Destes, quatro exemplares, pelas dimensões ou pela simplicidade do fundo, não permitiram a inclusão em nenhuma tipologia concreta. Também nesta categoria se identificaram três grupos de fabrico distintos (figura 6), o primeiro dos quais corresponde ao mais representado e é integrável no Grupo 1 do Estuário do Tejo. O grupo de fabrico 2 apresenta uma coloração entre o laranja e o castanho-escuro alaranjado, abundantes inclusões de pequena e média dimensão e um aspecto compacto e pouco depurado. Por fim, o grupo de fabrico 3, representado por apenas dois indivíduos, apresenta uma coloração castanha clara amarelada, tem abundantes inclusões de pequena e média dimensão e um aspecto compacto e depurado. 

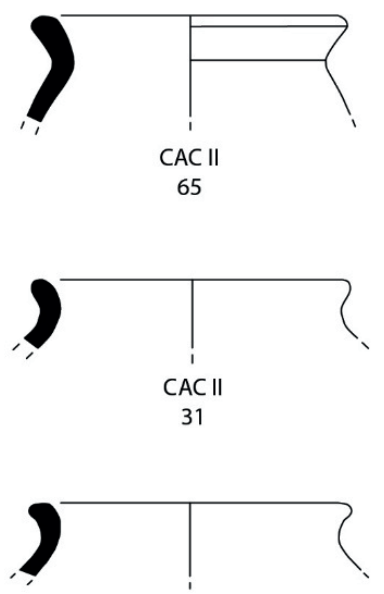

CACII

113

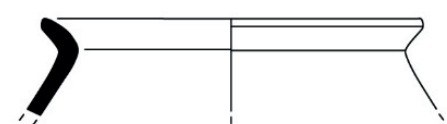

CAC II

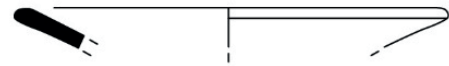

CAC
57
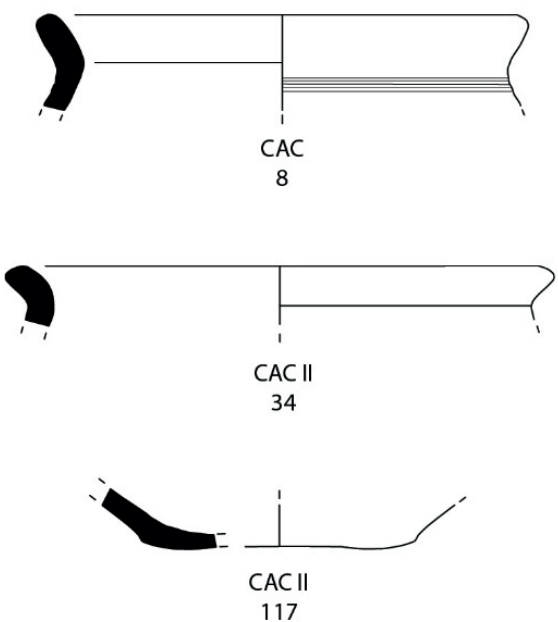

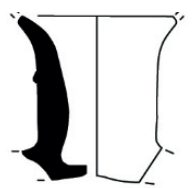

CAC II
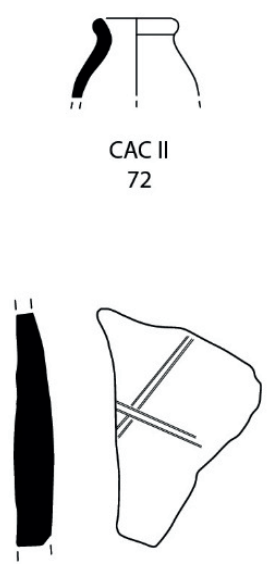

84

CAC II
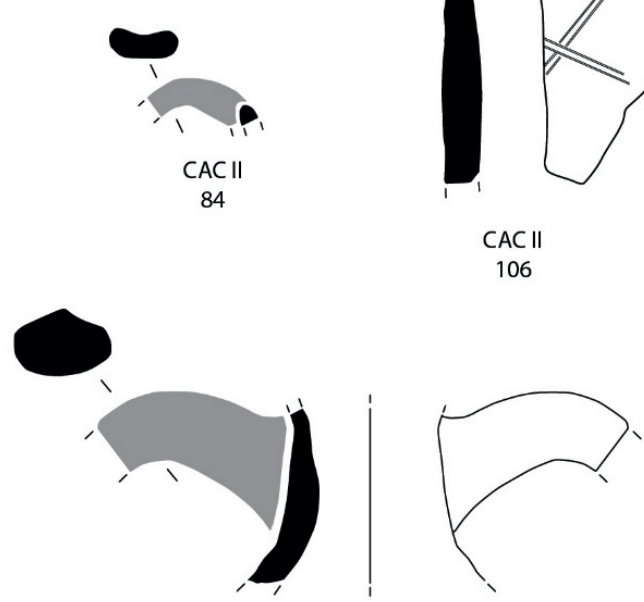

CAC II

104

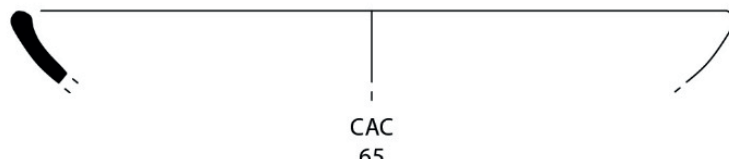

65

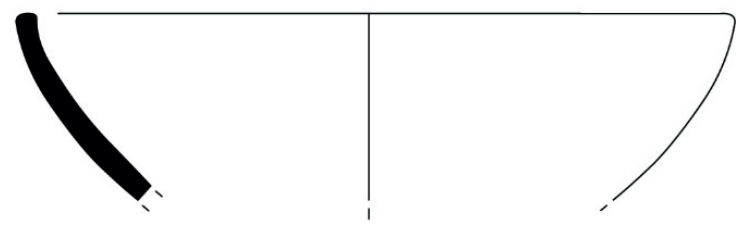

CAC II

6

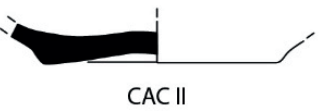

30

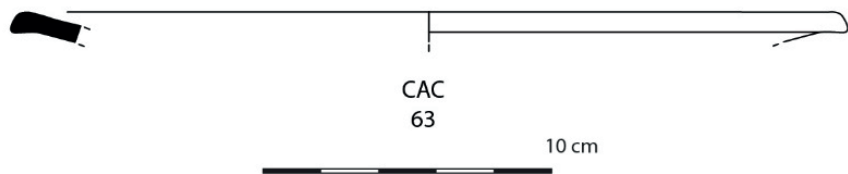

Figura 14 - Cerâmica comum. 
Do ponto de vista formal estão presentes dois vasos abertos, de tendência hemisférica, profundos e com o bordo ligeiramente espessado (figura 14: CACII 6, CAC 65), que têm correspondência na forma 1Aa do Tejo (Sousa, 2014, 151-152). Estas tigelas, pela simplicidade de perfil, integram o tipo mais estandardizado e estão com frequência documentadas em sítios ao longo de toda a diacronia da Idade do Ferro (Sousa, 2014, 151).

Outra tigela presente entre o acervo de Cacilhas apresenta um bordo de tendência convexa com um ligeiro espessamento (figura 14: CAC 57), que integra o tipo $1 \mathrm{Ab}$ definida para a Rua dos Correeiros (Sousa, 2014, 152).

Entre os recipientes abertos, em Cacilhas, está ainda presente uma outra tigela e um prato. A tigela ostenta um bordo aplanado com o lábio arredondado, com um sulco logo abaixo do bocal e uma parede côncava (figura 13: CACII 86). Esta forma não se enquadra na tipologia de referência para a Foz do Tejo e desconhecemos qualquer paralelo para a mesma. Quanto ao prato, este apresenta um bordo ligeiramente espessado, o lábio arredondado e uma parede recta e oblíqua (figura 14: CAC 57). Insere-se no tipo $3 \mathrm{Ba}$, que se encontra igualmente atestado na Rua dos Correeiros (Sousa, 2014, 158) e parece ainda registar-se em Freiria (Cardoso e Encarnação, 2013, 143).

Em Cacilhas identificou-se ainda uma peça que considerámos um suporte. O bordo é espessado com o topo aplanado e possui uma parede praticamente recta e oblíqua (figura 13: CAC 64), que enquadrámos na série 8 da tipologia criada para o Estuário do Tejo (Sousa, 2014). Este fragmento possui um bordo diferente dos exemplares conhecidos nos sítios desta região, pois apresenta o lábio aplanado e não arredondado (Sousa, 2014, 165-166), neste sentido, consideramos que se trata de uma variante distinta. Os suportes presentes na Rua dos Correeiros e em Santa Eufémia enquadram-se cronologicamente entre os finais do VI e o século V a.C. (Sousa, 2014, 165-166), datação que consideramos verosímil para a peça em análise. Não descartamos, contudo, que este elemento seja uma evidência do período romano, igualmente bem representado no sítio.

A forma mais representada entre o acervo de cerâmica comum de Cacilhas são os potes/panelas de bordo espessado e lábio arredondado, com o colo curto e estrangulado e de corpo globular ou ovoide (figura 14: CAC 8, CACII 31, 33, 34, 65 e 113). Esta morfologia enquadra-se no tipo $10 \mathrm{Aa}$ da tipologia criada para o Estuário do Tejo e encontra-se pre- sente em diversos sítios nessa região e ao longo de todo o $1^{\mathrm{o}}$ milénio a.C., mormente, na Quinta do Almaraz (Barros e Henriques, 2002, 307) e em Lisboa (Pimenta et al., 2014b, 714-715; Sousa, 2014).

Está igualmente presente outro pote/panela do tipo $10 \mathrm{~A}$, na variante $10 \mathrm{Aa} .2$, que possui uma asa a arrancar do bordo (figura 13: CACII 7). Este tipo de potes/panelas encontra-se também atestado na Quinta do Almaraz (Barros e Soares, 2004, 345), na Praça Nova (Sousa, 2014, 170), na Rua dos Correeiros (Sousa, 2014, 169-170) e no Moinho da Atalaia Oeste (Sousa, 2014).

Um fragmento de bordo pintado deverá inserir-se na Série 5 criada para a foz do Tejo, ou seja, uma bacia/alguidar, embora não encontremos qualquer paralelo concreto para a peça (figura 8: CACII 118). Também um fragmento de bojo com asa deverá corresponder a um jarro, que não conseguimos integrar em qualquer categoria da tipologia de cerâmica comum do vale do Tejo (figura 14: CACII 104). Como não possuímos contextos estratigráficos seguros não descartamos que esta peça seja um elemento de período Romano.

Regista-se ainda um indivíduo de vaso de perfil em S de muito reduzidas dimensões (figura 14: CACII 72). Desconhecemos qualquer paralelo para esta, no entanto, consideramos possível tratar-se de um pequeno pote para armazenar líquidos (unguentário?) ou uma miniatura de vasos de maiores dimensões.

Os restantes 3 fragmentos tratam-se de um bordo com arranque de asa (figura 14: CACII 84) e quatro fundos (figura 14) que, pelas reduzidas dimensões e simplicidade de perfil, não foram passíveis de classificação.

Por fim, destacamos uma das peças de cerâmica comum, que merece uma análise detalhada pela sua raridade. Trata-se de um provável fragmento de um queima-perfumes (denominado "pebetero" na bibliografia espanhola) de duplo prato, concretamente, o suporte que une o prato de cima ao de baixo, que seria o mais pequeno (figura 14: CACII $123)^{2}$. Estas peças são relativamente raras no território português, estando apenas presentes em Santa Olaia (Pereira, 1997, fig. 108), nos níveis arcaicos de Santarém (Arruda 2002: 215) e em Lisboa (Pimenta et al., 2014b, 716-717).

As características técnicas do fragmento de Cacilhas remetem-nos para as produções locais/regionais do vale do Tejo, o que parece coincidir com os

2 Agradecemos ao António Saéz Romero o apoio na classificação e comentários a esta peça. 
dados conhecidos para Cádis, onde as manufacturas são igualmente provenientes de ateliers regionais (Sáez Romero e Higueras-Milena Castellano, 2016, 66). A reduzida dimensão do fragmento em análise leva-nos a fazer esta classificação com reservas pois não excluímos a hipótese de se tratar de parte da base de uma taça de pé alto - embora esta proposta nos pareça pouco provável.

Esta morfologia tem uma origem oriental e foi recolhida em diversos estabelecimentos fenícios do ocidente peninsular, em contextos datados entre os séculos VIII e o V a.C., como por exemplo, em Cartago (Cintas, 1952), Trayamar (Niemeyer e Schubart, 1975), Villaricos (Lancel, 1968) e Cádiz (Muñoz Vicente, 1993; Saéz Romero e Higueras-Milena Castellano, 2016). Os queima-perfumes de duplo prato surgem sobretudo como parte dos rituais funerários, mas também em contextos industriais, habitacionais e cultuais, concretamente, vinculados a santuários de vocação marinha (Saéz Romero e Higueras-Milena Castellano, 2016, 67$70)$.

O fragmento em análise possui arestas limadas e regulares numa das extremidades, o que indicia que pode ter sido reutilizado para outras funções, porventura, como peso de rede.

\section{Cerâmica Manual}

A presença de cerâmica manual em contextos da Idade do Ferro no vale do Tejo é muito frequente desde fases recuadas de ocupação, como demonstram os dados da Rua de São Mamede ao Caldas $n^{0}$ 15 (Pimenta et al., 2014a) e da Sé de Lisboa (Arruda, 2000). Mantém-se atestada nos acervos das centúrias seguintes, embora com menor expressão, como indica sua presença na Rua do Correeiros (Sousa, 2014, 184-186) e Outurela 2 (Cardoso et al., 2014). Também na Quinta do Almaraz, povoado contíguo a Cacilhas, foi identificada olaria de manufactura manual num contexto denominado "fossa de detritos" (quadrado U45/3), cuja cronologia de enchimento, segundo a análise dos materiais, se enquadra entre o séc. V e o IV a.C. (Olaio, 2018) e onde representa 3,6 \% do total da cerâmica exumada (Barros et al., 1993, 156).

Entre o acervo de Cacilhas estão atestados 8 fragmentos de cerâmica manual (6 NMI) (figura 15), todos enquadráveis num único grupo de fabrico (figura 6) com coloração castanha escura acinzentada, abundantes inclusões de pequena, média e grande dimensão e um aspecto pouco compacto e não depurado.
A forma mais representada são os vasos abertos (CACII 80 e CACII 85), de tendência hemisférica, que correspondem a tigelas. Peças com as mesmas características estão presentes em Outurela 1 e 2 (Cardoso et al., 2014, 416), que se enquadram entre a segunda metade do séc. VI e o IV a.C. (Cardoso et al., 2014, 427).

Entre os vasos abertos encontra-se também atestado um prato, de bordo ligeiramente voltado para o exterior e um pouco engrossado, de perfil muito suave, com um diâmetro de $230 \mathrm{~mm}$ (CACII 77). Uma peça documentada na Rua do Recolhimento ostenta um perfil semelhante ao vaso que aqui apresentamos e está igualmente manufacturada manualmente (Sousa e Pinto, 2016, 62). Esta morfologia recorda os pratos em cerâmica de engobe vermelho, concretamente, a forma 3Aa da tabela tipológica criada por Elisa de Sousa para os sítios da margem norte do Tejo (Sousa, 2014, 121-122). Como referimos, esta forma está igualmente atestada em cerâmica de engobe vermelho em Cacilhas e na Quinta do Almaraz (Barros et al., 1993, 177). Do mesmo modo, as duas peças de bordo de potes/panela de perfil em $S$ estão igualmente atestadas entre o acervo de produção manual de Cacilhas (CACII 110 e 115).

A presença desta morfologia de pratos em cerâmica comum e em cerâmica de engobe vermelho parece indiciar uma produção para suprir carências das redes de abastecimento locais, hipótese que já tinha sido aventada para a Rua dos Correeiros (Sousa, 2014, 186) e Outurela 1 (Cardoso et al., 2014, 411).

O último fragmento de cerâmica manual classificado trata-se de um recipiente fechado, provavelmente um pote/panela, de bordo alto e ligeiramente voltado para o exterior (CACII 74). Esta peça assemelha-se a outra exumada no contexto 1 da Rua de São Mamede ao Caldas $\mathrm{n}^{\mathrm{0}} 15$, igualmente de produção manual (Pimenta et al., 2014a). O contexto 1 foi datado entre a segunda metade do século VIII e a primeira metade do VII a.C., através de um conjunto em que as manufacturas manuais constituíam 61\% do total da cerâmica (Pimenta et al., 2014a). Neste sentido, afigura-se relevante compreender, através do estudo de outros sítios de Almada, se esta morfologia se encontra em utilização desde os finais da Idade do Bronze ou se corresponderá a uma imitação dos pequenos potes de cerâmica cinzenta da forma 3Ac definida por Elisa de Sousa para a Rua dos Correeiros (Sousa, 2014), também representado no conjunto (CACII 100), sendo um novo elemento de que a manufactura manual poderia ser utilizada para suprir carências momentâneas das redes de abastecimento. 


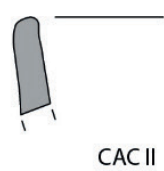

CAC II
85
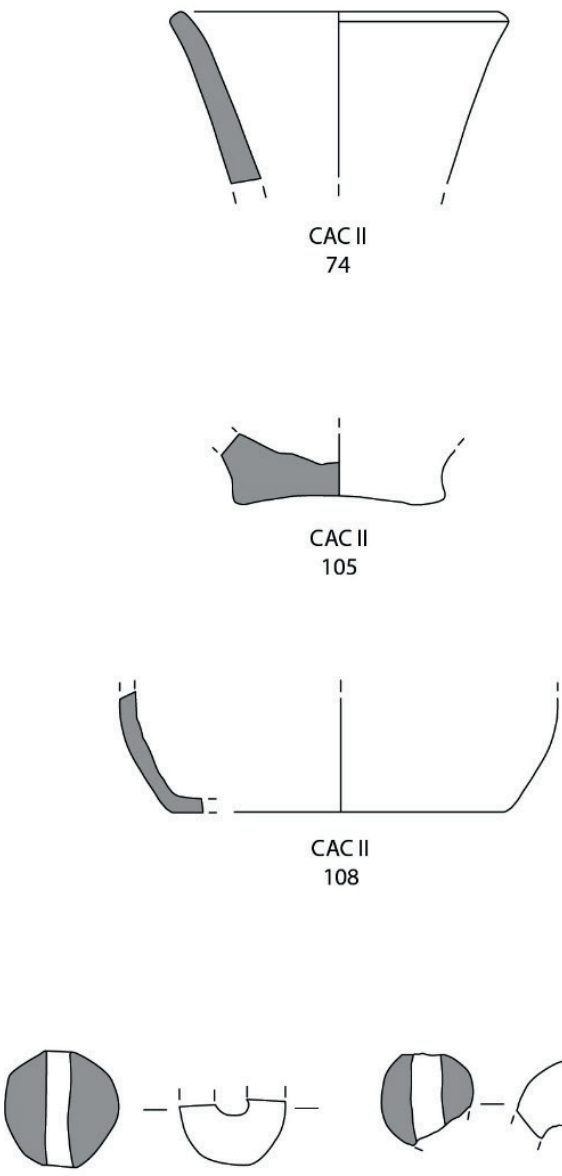

CACII

16

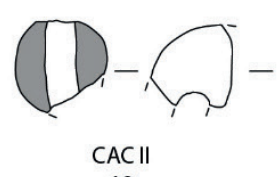

18

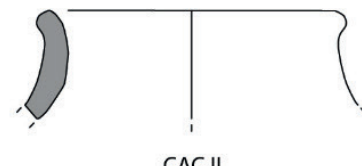

CAC II

115

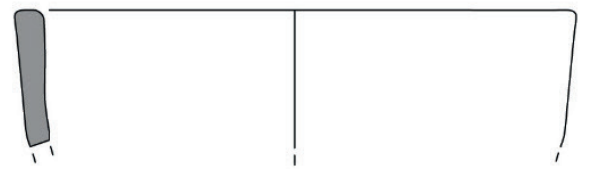

CAC II

80

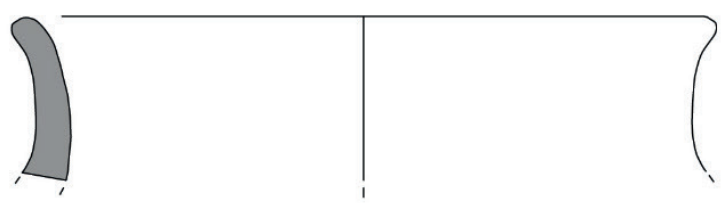

CAC II

110

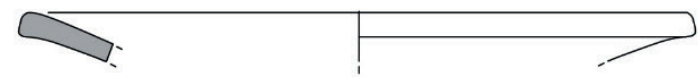

CAC॥

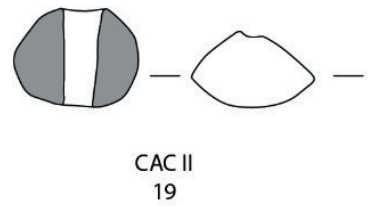

19

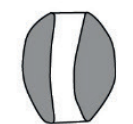

CAC II

15
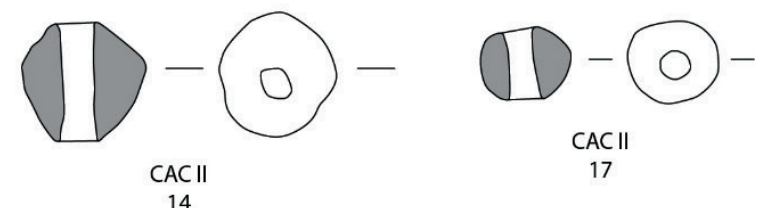

14<smiles></smiles>

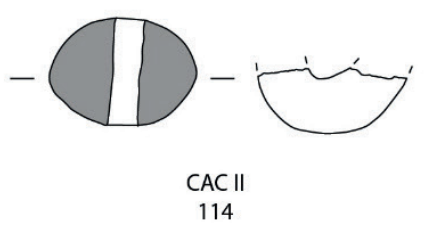

Figura 15 - Cerâmica manual e pesos de rede. 
Por fim, estão ainda presentes dois fragmentos de fundo que, pela dimensão e simplicidade, não conseguimos classificar (CACII 105 e CACII 108).
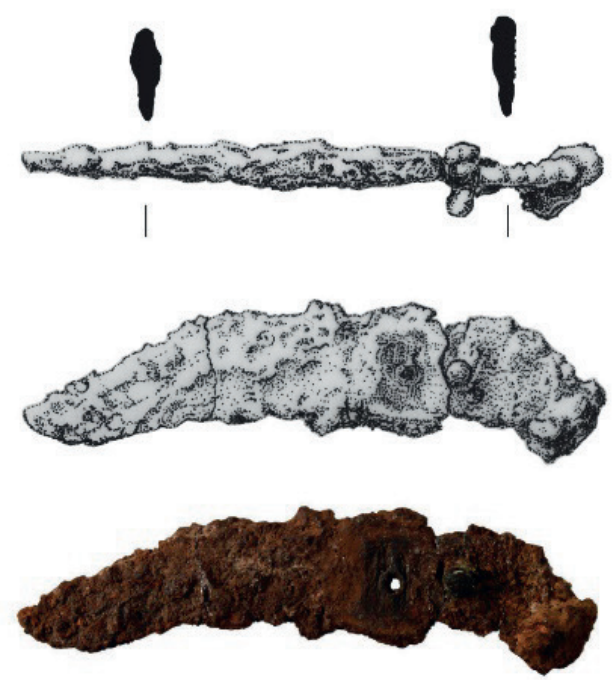

CAC II

5

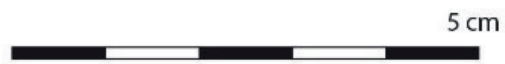

Figura 16 - Faca afalcatada em ferro (adaptado de Melo et al., 2014, 709).

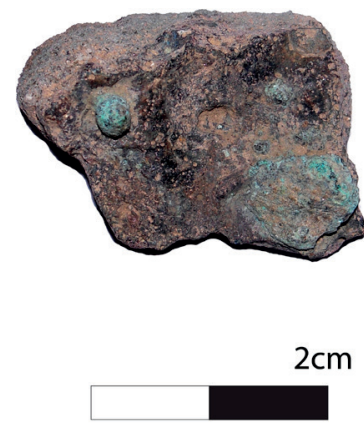

Figura 17 - Cadinho (CACII 3). Note-se a face interna muito escorificada, o nódulo esférico (canto superior esquerdo) e o nódulo disforme (canto inferior direito) analisados por micro espectrometria de fluorescência de raios $\mathrm{X}$, dispersiva de energias.
PESOS DE REDE EM CERÂMICA

Para além da baixela cerâmica foram identificados alguns artefactos associados às actividades desenvolvidas, entre eles, sete pesos de rede em cerâmica (figura 15).

A identificação enquanto pesos de rede (e não como cossoiros) prende-se essencialmente com as suas características, concretamente a falta de simetria e a irregularidade da perfuração central, que tornariam estes objectos inadequados para a tecelagem, tal como foi evidenciado noutros conjuntos (Cottica e Divari, 2010). Este tipo de pesos, associados à pesca com rede, é muito comum no registo proto-histórico, ainda que nem sempre surjam em grandes quantidades (Bernal Casasola, 2010). No povoado da Quinta do Almaraz estes também se encontram representados, a par de outros artefactos relacionados com a pesca, revelando uma actividade que seria natural num povoado com esta localização e acessibilidade ao rio e mar.

\section{MetAIs}

Além do conjunto cerâmico recolheu-se, nas escavações de Cacilhas, uma pequena faca afalcatada e um cadinho, ambos provenientes do interior dos muros de pedra seca (figura 5: "Estrutura 1"). Parece-nos relevante salientar, mais uma vez, a proximidade de Cacilhas relativamente ao povoado da Quinta do Almaraz, onde diversos estudos têm evidenciado a produção local de cobre, ferro, prata e, provavelmente, de ouro (Araújo et al., 2004; Valério et al., 2012; Melo et al., 2014). Estes dados conduziram a que fosse sugerida a existência, no local, de um importante centro metalúrgico, com uma ou várias oficinas (Melo et al., 2014, 710).

\section{FACA AFALCATADA}

Relativamente à pequena faca afalcatada de ferro recuperada em Cacilhas II (figura 16), esta possui cerca de seis centímetros de comprimento conservado. Na zona do guarda-mão apresenta dois rebites, um dos quais se conservou, sendo fabricado em liga de cobre. A peça foi publicada pela primeira vez nas Actas do IV Congresso de Estudos Fenícios e Púnicos em conjunto com outros artefactos metálicos ou relacionados com a produção metalúrgica da Quinta do Almaraz (Melo et al., 2014, 709).

A funcionalidade das facas afalcatadas tem sido debatida em torno das hipóteses de corresponderem a armas, objectos de uso quotidiano ou de uso ritual, não sendo possível afastar completamente qualquer 
uma das hipóteses (Mancebo, 2000). A sua possível funcionalidade diferenciada poderia eventualmente ser intuída pela existência de cabos de osso trabalhado, o que não parece ser o caso do exemplar aqui analisado, uma vez que este deveria ser de outra matéria mais perecível - como por exemplo, madeira. Cronologicamente, as pequenas facas afalcatadas de ferro ocorrem numa geografia e cronologia ampla, registando-se os primeiros exemplares, aparentemente, desde o século XI a.C. (Vilaça, 2013), ainda que alguns exemplares locais, registados na Quinta do Marcelo, também em Almada e próxima de Cacilhas, possam apontar para cronologias mais recentes, do século IX a.C. (Arruda, 2005, 29-30; Cardoso, 2004, 205-211).

\section{CADINHO METALÚRgICO}

O fragmento de cadinho cerâmico apresenta uma face interna muito escorificada e com nódulos de cor esverdeada (figura 17). A presença de uma camada de escória considerável sugere a utilização deste cadinho numa operação de redução de minérios, dado que a fusão de materiais metálicos resulta, normalmente, em vestígios cerâmicos menos escorificados (Rovira et al., 2009). Para além disto, a presença de um nódulo de forma esférica e dimensão considerável sugere a formação de uma verdadeira escória de baixa viscosidade no interior deste cadinho, contrariamente ao que regularmente se observa nos vestígios cerâmicos de operações metalúrgicas pré-históricas (Valério et al., 2013).

A análise por micro espectrometria de fluorescência de raios X, dispersiva de energias, dos nódulos esverdeados presentes na face interna do cadinho permitiu igualmente a obtenção de algumas inferências significativas. Em primeiro lugar, o nódulo esférico provou ser constituído por cobre e estanho, tendo então este cadinho sido utilizado para a produção de uma liga de bronze. Por outro lado, no nódulo disforme (figura 17) apenas foi identificada a presença de cobre, o que indica que este elemento entrou separadamente no processo metalúrgico. Tal exclui a possibilidade de fusão de sucata de bronze, algo que era já sugerido pela existência de uma camada significativa de escória no cadinho. Deste modo, uma opção possível para o método de produção de bronze neste cadinho será a co-redução de minérios de cobre e minérios de estanho. No entanto, apesar da escassez de lingotes de estanho no registo arqueológico, deste período, na Península Ibérica, a sua utilização (ver por exemplo: Mederos Martín e Ruíz Cabrero,
2004; Nieto e Santos, 2008), mesmo em períodos pré-históricos, parece cada vez mais plausível (Wang et al., 2016), razão pela qual não será de descartar a produção de bronze no cadinho cerâmico de Cacilhas através da cementação de minérios de cobre com lingotes de estanho.

\section{Discussão}

O sítio arqueológico de Cacilhas apresenta um considerável conjunto de vestígios relativos à Idade do Ferro. Das estruturas da Idade do Ferro identificadas nas intervenções destaca-se o muro interpretado como parte de um cais pré-romano (Barros e Henriques, 1998, 101-102). Esta proposta foi aventada porque a estrutura assentava directamente no substracto geológico, exibia características arquitectónicas distintas da fábrica romana e apresentava vestígios de erosão fluvial até cerca de um metro de altura (Barros e Henriques, 1998, 101-102).

Tendo em consideração o registo disponível, que não permite perceber, por exemplo, a cota a que a estrutura interpretada como cais pré-romano se encontrava, as suas dimensões, a relação com a fábrica de salga romana ou sequer os contextos associados, não cremos ter dados suficientes para confirmar ou refutar esta hipótese. Por outro lado, mesmo tendo em consideração os poucos dados disponíveis para a estrutura de Cacilhas, não se constatam afinidades com estruturas de cais identificadas, noutros locais, na mesma época (a título de exemplo, veja-se: Haggi e Artzy, 2007). Não obstante, a localização de Cacilhas num local com potencialidades naturais de ancoragem, acesso privilegiado ao Estuário do Tejo e ao denominado "mar da palha", bem como a configuração que a área teve até ao início do séc. $\mathrm{XX}$, com uma área de praia com areia até uma zona consideravelmente próxima ao local onde se encontra a fábrica de salga de peixe romana, torna o sítio propício a ser utilizado como área portuária.

Numa área contígua a esta, a cerca de $7 \mathrm{~m}$ de distância, foram intervencionados níveis da Idade do Ferro associados a três muros, de características afins aos identificados na Quinta do Almaraz, que parecem definir, pelo menos, um compartimento. Destes contextos, que parecem poder ser integráveis na Idade do Ferro pelo facto de apenas se registarem artefactos desta cronologia, provém a maioria do conjunto aqui analisado que, pelas suas características, nos parece compatível com uma ocupação de cariz doméstico.

A ligação com a Quinta do Almaraz afigura-se relevante para compreender a função deste local, 
parecendo-nos verosímil a hipótese de estarmos perante a continuação daquele povoado até ao rio. Estudos recentes relativos à Quinta do Almaraz indiciam um grande dinamismo do povoado durante o século VI a.C. (Olaio, 2018), o que poderá ter resultado na expansão da sua área até às margens do Tejo. Neste enquadramento, os vestígios de Cacilhas corresponderiam porventura a contextos habitacionais de apoio às actividades marítimo-fluviais do porto de Almaraz, que se localizaria naquela zona (independentemente da estrutura interpretada como cais o poder ser ou não). A presença dos pesos de pesca, ainda que em quantidades reduzidas, sugere-nos a ligação a estas actividades. O próprio queima-perfumes ("pebetero») poderá, tal como em locais como La Caleta (Saéz Romero e Higueras-Milena Castellano, 2016, 70), estar associado a algum ritual de vocação marinha - ainda que, no caso de Cacilhas, de âmbito doméstico.

Por outro lado, a presença do fragmento de cadinho para produção de bronze, assumindo que o contexto de proveniência é da Idade do Ferro (algo que, como já se mencionou, consideramos provável), traz mais dados para a compreensão dos métodos de produção metalúrgicos desenvolvidos à época, bem como para uma questão que já tem vindo a ser constatada noutros sítios da Península Ibérica, recentemente sintetizada por Ana Delgado Hervás, que se prende com a integração de actividades artesanais em espaços domésticos, sendo esta uma prática comum entre as comunidades fenícias ocidentais (Delgado Hervás, 2016, 72).

Fica por esclarecer se o povoado da Quinta do Almaraz se estenderia de forma contínua desde a zona mais alta até ao rio, algo que, ainda que possível, dificilmente será corroborado, visto que a plataforma onde se encontra foi bastante afectada nas vertentes Sul e Este, consequência não só do desenvolvimento urbano recente, como também da existência de uma pedreira que explorou o subsolo desde, pelo menos, a Idade Média até ao séc. XIX.

$\mathrm{O}$ conjunto cerâmico estudado permite, assim, centrar o início da ocupação da área de Cacilhas no século VI a.C., o que, como já referimos, parece coincidir com o período de maior dinamismo de Almaraz (Olaio, 2018). O abandono da área de Cacilhas, aparentemente durante os meados do século $\mathrm{V}$ a.C., concorda também com a perda de vitalidade do povoado (Olaio, 2015; Olaio, no prelo). Assinala-se, neste contexto, que este fenómeno acontece precisamente quando o povoado de Lisboa está no auge da sua expansão, com vestígios ao longo de 20 hectares (Sousa, 2017, 301).

Os dados inferidos do conjunto estudado, que se somam aos recentemente conhecidos para os sítios da Idade do Ferro do Estuário do Tejo, permitem ainda confirmar um desenvolvimento precoce de uma produção local/regional de vários tipos cerâmicos (contentores, cerâmica de mesa, cerâmica comum, ...) já plenamente desenvolvida e consolidada no século VI a.C..

Conforme indica o peso das produções locais/ regionais nos conjuntos publicados da Idade do Ferro na área do Baixo Tejo, a zona parece ter-se tornado, desde cedo, praticamente independente da esfera do comércio mediterrâneo. Este fenómeno torna-se particularmente evidente quando observamos o número de ânforas importadas. Registam-se, até à data, 60 importações de ânforas do tipo 10.1.1.1 e 10.1.2.1, em todo o Baixo Tejo, valor que não se aproxima da carga máxima de uma embarcação (veja-se, a título de exemplo: Ballard et al., 2002, 151-168). Estes dados afiguram-se bastante elucidativos já que se tratam de dois contentores que foram produzidos e comercializados ao longo de cerca de dois séculos, concretamente, entre os meados ou segundo quartel do VIII e a primeira metade do VII a.C.; e o séc. VII e os meados do VI a.C., respectivamente (Ramon Torres, 1995, 229-231).

À luz dos dados disponíveis, é dificilmente sustentável falar de "contactos intensos" com o Mediterrâneo ao longo da primeira metade do milénio, como alguns autores têm sugerido (Sousa, 2017, 296). A escassez de importações, aliada à precoce adopção da tecnologia e conceitos produtivos exógenos, demonstra uma chegada de populações com esses conhecimentos técnicos, que, aparentemente, se misturam rapidamente com o tecido social local e deixam de depender do seu lugar de origem. Esta chegada de pessoas foi já sugerida por diversos autores para explicar as alterações ocorridas no início da chamada Idade do Ferro (por exemplo: Arruda, 1999-2000; Arruda et al., 2017), ficando por perceber a verdadeira dimensão do fenómeno.

Parece-nos, pois, relevante compreender o modo como se efectuou o contacto entre indígenas e as populações exógenas. Alguns autores têm defendido um modelo de cariz predominantemente colonial em que existe uma imposição, pactuada ou não, de tecnologias, morfologias e até do elemento "identitário por excelência", a língua (Arruda, 2017; Arruda et al., 2017). A descoberta, em Lisboa, 
de uma inscrição funerária em escrita fenícia, datada do século VII a.C., pertencente a um indivíduo de filiação local (Neto et al., 2016, 126), que se junta à inscrição sobre ânfora identificada durante as escavações da Praça Nova do Castelo de São Jorge, paleograficamente datada do final do séc. VIII a.C. (Arruda, 2013, 222; Zamora López, 2013, 363; Arruda, 2017, 285), parecem suportar esta hipótese.

Por outro lado, a introdução da planimetria ortogonal na construção - que se limita, até ao momento, à zona correspondente ao Baixo Tejo (Vilaça e Cardoso, 2017, 246) -, ou a própria introdução e rápida adopção do torno e de novas morfologias, indiciam uma preponderância do elemento exógeno. A chegada dos contingentes externos e alterações decorrentes teve inclusivamente consequências no hinterland, de que é demonstrativo o intensificar da desflorestação nas áreas do Estuário do Tejo (Leewaarden e Jansen, 1985; Arruda, 2003), num fenómeno semelhante ao sucedido em Cerro del Vilar (Aubet et al., 1999). Neste contexto, há um aparente "papel secundário" para as populações autóctones, para as quais este "novo modelo de organização social e política, que a colonização fenícia implicou, foi certamente "dolorosa" e em muitos casos não inclusiva” (Arruda et al., 2017, 88).

Não obstante, o desenvolvimento, logo nos primeiros momentos da influência fenícia no Estuário do Tejo, de uma autonomia económica e capacidade de auto-abastecimento, que denunciam uma estrutura económica bem consolidada, parece ser revelador da existência de uma sociedade predisposta a absorver essas novas tecnologias, com uma organização prévia na qual os novos elementos externos se inserem. Isto é, afigura-se verosímil que, no Baixo Tejo, o elemento exógeno se insira numa estrutura política consolidada prévia - da qual o povoamento aparentemente bem hierarquizado e organizado do Bronze Final, nesta área, é revelador (Vilaça e Cardoso, 2017, 245) -, sem a qual seria mais morosa a adopção generalizada da tecnologia e dos novos hábitos e tradições.

É importante salientar que os contactos entre as populações indígenas e os mercadores orientais estão atestados desde o Bronze Final, momento em que se inicia a incorporação de elementos e hábitos exógenos, ainda que de forma selectiva (Vilaça, 2011, 164; Cardoso, 2015, 152-153; Vilaça e Cardoso, 2017, 271). Desde a importação de "bens de prestígio" (Vilaça e Arruda, 2004) à adopção do "padrão" de peso oriental (Vilaça, 2011, 164), constata-se o início da integração das novidades, antes mesmo do estabelecimento de populações vindas do Mediterrâneo.

Neste sentido, julgamos ser necessário reflectir sobre a possibilidade da chegada de populações orientais ser desejada, incentivada ou pactuada com as populações locais do Estuário do Tejo, já que, como referimos, parece-nos pouco provável que todas as alterações introduzidas (e, principalmente, a rapidez da adopção das mesmas) se coadune com o modelo colonial "clássico", no qual as populações indígenas são meros espectadores.

Este processo de alteração económica, política e social que cremos estar em grande parte por explicar e que começa ainda no final da Idade do Bronze, mas, sobretudo, com a chegada e fixação de populações oriundas do Mediterrâneo nos finais do século VIII/inícios do século VII a.C., em cronologia tradicional, parece estar plenamente implementado no século VI a.C.. Nesta fase temos uma estrutura económica consolidada e auto-suficiente no Estuário do Tejo, com raros elementos importados, mantendo-se, contudo, ao longo de todo o $1^{o}$ milénio a.C., os contactos culturais com o Mediterrâneo, como demonstram as ânforas importadas, as cerâmicas que emulam modelos helénicos (Sousa e Pimenta, 2017) ou as próprias cerâmicas gregas (Arruda, 1997, 85-87; Cardoso, 2004, 263; Pimenta et al., 2005, 321; Sousa, 2014, 110-113).

\section{Agradecimentos}

À Divisão de Museus da Câmara Municipal de Almada pela cedência do conjunto e registos de escavação. Ao Departamento de Conservação e Restauro (FCT-UNL) pela utilização do espectrómetro de micro-EDXRF. Ao Luís Barros pelas informações e documentos cedidos sobre Cacilhas e ao Fernando Henriques por todos os esclarecimentos.

\section{Bibliografia}

Almagro-Gorbea, M. (1977), El bronce final y el Periodo Orientalizante en Extremadura, Biblioteca Praehistórica Hispánica 14, Madrid.

Almagro-Gorbea, M., Mederos Martín, A. y Torres Ortiz, M. (2008), "Cerámica de barniz rojo", La Necrópolis de Medellín. II- Estudio de los Hallazgos (Almagro-Gorbea, M. Dir.), Madrid, 593-622.

Araújo, M., Barros, L., Teixeira, A. y Melo, A. (2004), "EDXRF study of Prehistoric artefacts from Quinta do Almaraz (Cacilhas, Portugal)”, 
Nuclear Instruments and Methods in Physics Research B, 213, 741-746.

Arruda, A.M. (1997), A cerâmica ática do Castelo de Castro Marim, Lisboa.

Arruda, A.M. (1999-2000), Los Fenícios en Portugal. Fenícios y mundo indígena en el centro y sur de Portugal (siglosVIII-VI a.C.), Cuadernos de Arqueologia Mediterránea, 5-6, Barcelona.

Arruda, A.M. (2003), "Contributo da colonização fenícia para a domesticação da terra portuguesa”, Ecohistoria del paisaje agrario - la agricultura fenicio-púnica en el Mediterráneo, Valencia, 205-217.

Arruda, A.M. (2005), “O 1. ${ }^{\circ}$ milénio a.n.e. no Centro e no Sul de Portugal: leituras possíveis no início de um novo século”, O Arqueólogo Português, 4, 23, 9-156.

Arruda, A.M. (2014), "A Oeste tudo de novo: novos dados e outros modelos interpretativos para a orientalização do território português", Fenícios e Púnicos, Por Terra e Mar (Arruda, A. M. Ed.), Lisboa, 512-535.

Arruda, A.M. (2017), "A Idade do Ferro Orientalizante no Vale do Tejo: As duas margens de um mesmo rio", Territorios Comparados: Los valles del Guadalquivir, el Guadiana y el Tajo en época tartésica (Celestino Pérez, S. y Rodríguez, E., Eds.), Madrid, 283-294.

Arruda, A.M., Freitas, V. y Sánchez, J. (2000), “As cerâmicas cinzentas da Sé de Lisboa", Revista Portuguesa de Arqueologia, 3/2, 25-59.

Arruda, A.M., Sousa, E., Pimenta, J., Mendes, H. y Soares, R. (2014), “Alto do Castelo's Iron Age Occupation (Alpiarça, Portugal)”, Zephyrus, LXXIV, 143-155.

Arruda, A.M., Oliveira, C. y Freitas, V. (2017) "Castro Marim entre indígenas, Fenícios e Tartéssicos”, Sidereum Ana III: el rio Guadiana y Tartessos (Jiménez Ávila, J. Ed.), Mérida, 443-466.

Arruda, A.M., Sousa, E., Pimenta, J., Soares, R. y Mendes, H. (2017), "Fenícios e Indígenas em Contacto no Estuário do Tejo”, Ophiussa, 1, 79-90.

Aubet, M., Carmona, P., Curia, E., Delgado, A., Férnandez Cantos, A. y Párraga, M. (1999), Cerro del Villar - 1. El asentamiento fenício en la desembocadura del rio Guadalhorce y su interacción com el hinterland, Sevilha.

Ballard, R., Stager, L., Master, D., Yoerger, D.,
Mindell, D., Whitcomb, L., Singh, H. y Piechota, D. (2002), "Iron Age Shipwrecks in Deep Water of Ashkelan, Israel", American Journal of Archaeology, 106, 2, 151-168.

Barceló, J. A., Delgado, A.; Fernández, A. y Párraga, M. (1995), "El área de producción alfarera del Cerro del Villar (Guadalhorce, Málaga)”, Rivista di Studi Fenici, XXIII, 2, 147-182.

Barros, L. (1982), "Cacilhas: uma experiência de arqueologia urbana.”, Al-madan, N. ${ }^{\circ} 0,34-35$.

Barros, L. (1998), Introdução à Pré e Proto História de Almada, Almada.

Barros, L., Amaro, C. (1985), "Fábrica de salga de peixe em Cacilhas - achegas para o seu conhecimento", Al-madan, N. ${ }^{-4}$-5, 33-34.

Barros, L., Cardoso, J. L. y Sabrosa, A. (1993), "Fenícios na margem Sul do Tejo. Economia e integração cultural do povoado de Almaraz - Almada”, Estudos Orientais, IV, 143-173.

Barros, L. y Henriques, F. (1998), "Vestígios de um cais pré-romano em Cacilhas", Actas das $2^{a}$ Jornadas de estudos sobre o concelho de Almada ( Santos, M. y Antunes, L. Eds.), Almada, 105-105.

Barros, L. y Henriques, F. (2002), “Almaraz, primeiro espaço urbano em Almada”, Actas do $3^{\circ}$ Encontro Nacional de Arqueologia Urbana (Henriques, F., Santos, M. e António, T., Eds.), Almada, 295-311.

Barros, L. y Soares, A.M. (2004), "Cronologia absoluta para a ocupação orientalizante da Quinta do Almaraz”, O Arqueólogo Português, 4. 22, 333-352.

Belén, M. y Pereira, J. (1985), "Cerámicas a torno con decoración pintada en Andalucía”, Huelva Arqueológica, 7, 307-360.

Bernal Casasola, D. (2010), "Fishing Tackle in Hispania: Reflections, Proposals and Firts Results", Ancient Nets and Fishing Gear - Proceedings of the Internacional Workshop on Nets and Fishing Gear in Classical Antiquity: a First Approach (Bekker-Nielsen, T. y Bernal Casasola, T., Eds.), Cádiz, 83-138.

Bugalhão, J. (2001), A indústria romana de transformação e conserva de peixe em Olisipo. Núcleo Arqueológico da Rua dos Correeiros, Trabalhos de Arqueologia 15, Lisboa.

Calado, M. (2008), Olisipo pré-romana - Um ponto da situação, Lisboa.

Calado, M., Pimenta, J., Fernandes, L. y Filipe, V. 
(2013), "Conjuntos cerâmicos da Idade do Ferro do Teatro Romano de Lisboa: as cerâmicas de engobe vermelho", Arqueologia em Portugal, 150 anos - Actas do I Congresso dos Arqueólogos Portugueses (Arnaud, J., Martins, A. y Neves, C.), Lisboa, 641-649.

Cardoso, J.L. (2004), A Baixa Estremadura dos finais do IV milénio A.C. até à chegada dos Romanos: um Ensaio de História Regional, Estudos Arqueológicos de Oeiras 12, Oeiras.

Cardoso, J.L. (2015), "Between the Atlantic and the Mediterranean: the Late Bronze Age around the Tagus estuary (Portugal). Economic, social and cultural aspects", Rivista di Scienze Preistoriche, LXV, 149-170.

Cardoso, J.L. y Silva, C. T. (2010/2011), "O casal agrícola da I Idade do Ferro do Leião (Oeiras)”, Estudos Arqueológicos de Oeiras, 8, 75-102.

Cardoso, J.L., Arruda, A.M., Sousa, E. y Rego, M. (2014), "Outurela I e Outurela II, dois pequenos sítios da Idade do Ferro a norte do Estuário do Tejo (concelho de Oeiras)", Estudos Arqueológicos de Oeiras, 21, 115-151.

Cardoso, J.L., Carvalhosa, A., Sousa, E., Bugalhão, J. y Sequeira, M.J. (2017), "Caracterização mineralógica de cerâmicas da Idade do Ferro de Lisboa (Núcleo Arqueológico da Rua dos Correeiros)", Revista Portuguesa de Arqueologia, 20, 71-82.

Cardoso, G. (1991), Carta Arqueológica do Concelho de Cascais, Cascais.

Cardoso, G. y Encarnação, J. (2013), "O povoamento pré-romano de Freiria - Cascais”, CIRA Arqueologia, 2, 33-180.

Cintas, P. (1950), Cerámique punique de Cartago, Tunez.

Contreras, F., Carrion, F. y Jabaloy, E. (1983), “Un horno de alfarero protohistórico en el Cerro de Los Infantes (Pinos Puente, Granada)", Crónica del XVI Congreso Arqueológico Nacional, Zaragoza, 533-537.

Cottica, D. y Divari, L. (2010), "Spheroid clay weights from the Venetian Lagoon", Proceedings of the Internacional Workshop on Nets and Fishing Gear in Classical Antiquity: a First Approach (Bekker-Nielsen, T. y Bernal Casasola, D., Eds.), Cádiz, 347-363.

Delgado Hervás, A. (2016), "Producción artesanal y trabajo femenino en las comunidades fenicias occidentales: una mirada crítica a la teoría de las esferas separadas", Los trabajos de las mujeres en el mundo antiguocuidado y mantenimiento de la vida (Delgado Hervás, A. y Picazo Gurina, M., Eds.), Tarragona, 67-161.

Encarnação, J. y Cardoso, G. (2017), "O sítio arqueológico do Espigão das Ruivas (Cascais)”, Actas do II Congresso da Associação dos Arqueólogos Portugueses: Arqueologia em Portugal - O Estado da Questão (Arnaud, J. y Martins, A., Eds.), Lisboa, 955-966.

Fernandes, L., Pimenta, J., Calado, M. y Filipe, V. (2013), "Ocupação sidérica na área envolvente do teatro romano de Lisboa: o Pátio do Aljube”, Revista Portuguesa de Arqueologia, 16, 167185.

Filipe, V., Calado, M. y Leitão, M. (2014), "Evidências orientalizantes na área urbana de Lisboa. $\mathrm{O}$ caso dos edifícios na envolvente da Mãe de Água do Chafariz d'El Rei”, Fenícios e Púnicos, por terra e mar. Actas do VI Congresso Internacional de Estudos Fenícios e Púnicos (Arruda, A. M., Ed.), Lisboa, 736-747.

Frankenstein, S. (1997), Arqueología del colonialismo: el impacto fenicio y griego en el sur de la Península Ibérica y el suroeste de Alemania, Barcelona.

Freitas, V. (2005), As cerâmicas de engobe vermelho do Castelo de Castro Marim: produção, consumo e comércio na Idade do Ferro Orientalizante Peninsular, Tese de Mestrado apresentada à Faculdade de Letras da Universidade de Lisboa.

Gago Vidal, M., Clavaín González, I., Muñoz Vicente, A., Perdigones Moreno, L. y Frutos Reyes, G. (2000), "El complejo industrial de salazones Gaditano de Camposoto, San Fernando (Cádiz): Estudio preliminar", Habis, 31, 37-61.

Gomes, F. y Antunes, L. P. (1985), "Intervenções de salvamento em Almada. Problemas de crescimento e alteração ao traçado urbano tradicional", Actas do I Encontro Nacional de Arqueologia Urbana, Lisboa, 69-79.

Haggi, A. y Artzy, M. (2007), “The Harbor of Atlit in Northern Canaanite/Phoenician Context”, Near Eastern Archaeology, 70, 2, 75-54.

Henriques, S. (2006), A cerâmica cinzenta da Idade do Ferro da Quinta do Almaraz (Almada, Cacilhas), Tese de Mestrado em Arqueologia apresentada à Faculdade de Letras da Universidade de Lisboa.

Lancel, S. (1968), “Tipasitana III: La necrópole préromaine occidentale de Tipasa", Bulletin d'Ar- 
chaeologie Algérienne, 3, 85-167.

Lavado, M.L. (1999), "La cerámica del horno del estrato II.”, Cerro del Villar - I. El Asentamiento Fenicio en la Desembocadura del Río Guadalhorce y su Interacción con el Hinterland (Aubet, M. E., Carmona, P. Curià, E., Delgado, A., Férnandez Cantos, A. y Párraga, M., Eds), Andalucia, 128- 136.

Leewarden, W. y Jansen, C. (1985), “A preliminary palynological study of a peat deposit near na oppidum in the lower Tagus valley, Portugal", Actas da I Reunião do Quaternário Ibérico, Lisboa, 225-235.

Mancebo, J. (2000), “Análisis de los objetos metálicos en el Período Orientalizante y su conexión con el mundo fenicio. Los cuchillos afalcatados", Actas del IV Congreso Internacional de Estudios Fenicios y Púnicos 4, Cádiz, 1825-1834.

Mayet, F. y Silva, C.T. (1993), "Presença fenícia no Baixo Sado", Estudos Orientais, 4, 127-142.

Mayet, F. y Silva, C.T. (2000), Le site phénicien d'Abul (Portugal). Comptoir et Sanctuaire Comptoir et Sanctuaire, Paris.

Melo, A., Valério, P., Barros, L. y Araújo, M.F. (2014), "Práticas metalúrgicas na Quinta do Almaraz (Cacilhas, Portugal): vestígios orientalizantes", Fenícios e Púnicos, por terra e mar. Actas do VI Congresso Internacional de Estudos Fenícios e Púnicos (Arruda, A. M., Ed.), Lisboa, 699-711.

Mederos Martín, A. y Ruiz Cabrero, L.A. (2004) "El pecio fenicio del Bajo de la Campana (Murcia, España) y el comercio del marfil norteafricano", Zephyrus, 57, 263-281.

Muñoz Vicente, A. (1993), "Las cerâmicas fenicio-púnicas de origen submarino del área de La Caleta (Cádiz)", Cuadernos de Prehistoria y Arqueología Castellonenses 15, 297-334.

Neto, N., Rebelo, P., Ribeiro, R., Rocha, M. y Zamora López, J. (2016), “A inscrição lapidar fenícia em Lisboa”, Revista Portuguesa de Arqueologia, 19, 123-128.

Niemeyer, H. y Schubart, H. (1975), Trayamar. Die Phonizischen Kammergraber und die Niederlassund and der Algarrobo-Mundung, Mainz.

Nieto, X. y Santos, M. (2008), El Vaixell Grec Arcaic de Cala Sant Vicenç, Girona. Barcelona.

Olaio, A. (2018), "O povoado da Quinta do Almaraz (Almada, Portugal) no âmbito da ocupação do Baixo Tejo durante o $1^{0}$ milénio a.n.e.: os dados do conjunto anfórico. Spal, 27.2, 103-141.

Olaio, A. (no prelo), "O povoado da Quinta do Almaraz (Almada, Portugal) no âmbito da ocupação no Baixo Tejo durante o $1^{0}$ milénio a.n.e.: os dados do conjunto anfórico".

Paixão, A.C. (1970), A necrópole do Senhor do Mártires, Alcácer do Sal - Novos elementos para o seu estudo, Tese de Licenciatura apresentada à Faculdade de Letras da Universidade de Lisboa.

Pereira, I. (1997), "Santa Olaia et le comerse atlantique”, Itineraires Lusitaniens: Trente années de collaboration archéologique luso-française-Actes de la reunion, Bordeaux, 209-253.

Pérez Hormaeche, E. (1990), “Arqueología Gaditana I: quemaperfumes púnicos”, Gades, 19, 9-23.

Pimenta, J., Calado, M. y Leitão, M. (2014a), “Sobre a ocupação pré-romana de Olisipo. A intervenção arqueológica urbana da Rua de São Mamede ao Caldas n. ${ }^{\circ}$ 15", Fenícios e Púnicos, por terra e mar. Actas do VI Congresso Internacional de Estudos Fenícios e Púnicos (Arruda, A. M., Ed.), Lisboa, 724-735.

Pimenta, J., Calado, M. y Leitão, M. (2014b), “Novos dados sobre a ocupação pré-romana da cidade de Lisboa. A intervenção da Rua de São João da Praça”, Fenícios e Púnicos, por terra e mar. Actas do VI Congresso Internacional de Estudos Fenícios e Púnicos (Arruda, A. M., Ed.), Lisboa, 712-723.

Pinto, C. y Parreira, R. (1978), "Contribuição para o Estudo do Bronze Final e Ferro Inicial a Norte do Estuário do Tejo”, Actas das III Jornadas Arqueológicas da Associação dos Arqueólogos Portugueses, Lisboa, 147-163.

Ramon Torres, J. (1995), Las ánforas fenicio-púnicas del Mediterráneo Central y Occidental, Collecció Instrumenta, 2, Barcelona.

Rovira, S., Montero-Ruíz, I. y Renzi, M. (2009), "Experimental co-smelting to copper-tin alloys", Metals and Societies. Studies in Honour of Barbara S. Ottaway - Universitätsforschungen zur Prähistorischen Archäologie (Kienlin, T. L. y Roberts, B. W., Eds.), Bonn, 407-414.

Rufete Tomico, P. (1988/1989), "Las ceramicas con egobe rojo de Huelva", Huelva Arqueológica, X-XI, 3, 10-40.

Ruiz Mata, D. (1987), "Informe sobre las excavaciones sistemáticas realizadas en el yacimiento del 
Castillo de Doña Blanca (Puerto de Santa María, Cádiz)”, Anuario arqueológico de Andalucía/1985,II, 360-365.

Ruiz Mata, D. y Pérez Pérez, C. (1995), El poblado fenício del Castillo de Doña Blanca (El Puerto de Santa María, Cádiz), Cádiz.

Saéz Romero, A. y Higueras-Milena Castellano, A. (2016), "Pebeteros inéditos de época fenicio-púnica procedentes de La Caleta (Cádiz): estúdio de las piezas y consideraciones historiográficas”, Revista atlánticoa-mediterránea de arqueología social, 18, 61-74.

Sousa, E. (2014), A ocupação pré-romana da foz do Estuário do Tejo, Estudos e Memórias 7, Lisboa.

Sousa, E. (2016), “A Idade do Ferro em Lisboa: Uma primeira aproximação a um faseamento cronológico e à evolução da cultura material", CUPAUAM, 42, 167-185.

Sousa (2017), "Percorrendo o Baixo Tejo: Regionalização e identidades culturais na $2^{\mathrm{a}}$ metade do $1^{0}$ milénio a.C.", Territorios comparados: los valles del Guadalquivir, el Guadiana y el Tajo en la época tartésica (Celestino Pérez, S. y Rodríguez González, E., Eds.), Mérida, 295318.

Sousa, E. y Pimenta, J. (2014), “A produção de ânforas no Estuário do Tejo durante a Idade do Ferro”, As Produções cerâmcias de Imitação na Hispânia (Morais, R.; Fernández, A. y Sousa, M., Eds.), Porto, 267-279.

Sousa, E. y Pinto, M. (2016), “A ocupação da Idade do Ferro na colina do Castelo de São Jorge (Lisboa, Portugal): novos dados das escavações realizadas na Rua do Recolhimento/Beco do Leão", Apontamentos de Arqueologia e Património, 11, 59-67.

Sousa, E. y Pimenta, J. (2017), Produções cerâmicas de inspiração grega no Vale do Baixo Tejo, Actas do II Congresso da Associação dos Arqueólogos Portugueses: Arqueologia em Portugal - O Estado da Questão (Arnaud, J. y Martins, A., Eds.), Lisboa, 887-896.

Torres Ortiz, M. (2002), Tartessos, Madrid.

Torres Ortiz, M. (2008), "Urnas de Tipo Cruz del Negro”, La necrópolis de Medellín. II - Estudio de los hallazgos (Almagro Gorbea, M., Lorrio, A., Mederos, A. y Torres Ortiz, M., Eds.), Madrid, 631-653.

Valério, P., Silva, R.J.C., Araújo, M.F., Soares,
A.M.M.; Barros, L. (2012), “A multianalytical approach to study the Phoenician bronze technology in the Iberian Peninsula - A view from Quinta do Almaraz", Materials Characterization, 67, 74-82.

Valério, P., Soares, A.M.M., Silva, R.J.C., Araújo, M.F., Rebelo, P., Neto, N., Santos, R. y Fontes, T. (2013), "Bronze production in Southwestern Iberian Peninsula: the Late Bronze Age metallurgical workshop from Entre Águas 5 (Portugal)", Journal of Archaeological Science, 40 (1), 439-451.

Vilaça, R. (2011), "Ponderais do Bronze Final Ferro Inicial no Ocidente Peinsular: Novos dados e questões em aberto", Barterm money and coinage in the ancient Mediterranean (10th - 1st centuries BC), García Bellido, M., Callegarin, L., Jiménez Díez, A., Eds.), Madrid, 139-167.

Vilaça, R. (2013), "Contextes d'utilisation, de circulation et de déposition des premiers artefacts en fer de l'Atlantique occidental', L'Âge du Fer en Aquitaine et sur ses marges. Mobilité des hommes, diffusion des idées, circulation des biens dans l'espace européen à l'Age du Fer, Actes du 35e Colloque Internationale (Colin, A. y Verdin, F., Eds.), Bordeaux, 631-642.

Vilaça, R. y Arruda, A.M. (2004), "Ao longo do Tejo, do Bronze ao Ferro”, Conimbriga, XLII, 11-45.

Vilaça, R. y Cardoso, J.L. (2017), "O Tejo Português durante o Bronze Final”, Territorios comparados: los valles del Guadalquivir, el Guadiana y el Tajo en la época tartésica. (Celestino Pérez, S. y Rodríguez González, E. Eds.), Mérida, 237-281.

Zamora, J.A. (2014), Novedades de epigrafía feniciopúnica en la Península Ibérica y sus aledaños, Palaeohispanica, 13, 359-384.

Wang, Q., Strekopytov, S., Roberts, B.W. y Wilkin, N. (2016), "Tin ingots from a probable Bronze Age shipwreck off the coast of Salcombe, Devon: Composition and microstructure", Journal of Archaeological Science, 67, 80-92. 
